\title{
Monitoring Sea Level and Topography of Coastal Lagoons Using Satellite Radar Altimetry: The Example of the Arcachon Bay in the Bay of Biscay
}

\author{
Edward Salameh 1,2,*(D), Frédéric Frappart ${ }^{1,3}$, Vincent Marieu ${ }^{4}$ (D), Alexandra Spodar ${ }^{4,5}$, \\ Jean-Paul Parisot ${ }^{4}$, Vincent Hanquiez ${ }^{4}$, Imen Turki ${ }^{2}$ and Benoit Laignel ${ }^{2}$ \\ 1 Laboratoire d'Etudes en Géophysique et Océanographie Spatiales (LEGOS), Université de Toulouse, IRD, \\ CNES, CNRS, UPS, 31400 Toulouse, France; frederic.frappart@legos.obs-mip.fr \\ 2 Normandie University, UNIROUEN, UNICAEN, CNRS, M2C, Morphodynamique Continentale et Côtière, \\ 76000 Rouen, France; imen.turki@univ-rouen.fr (I.T.); benoit.laignel@univ-rouen.fr (B.L.) \\ 3 Géosciences Environnement Toulouse (GET), Université de Toulouse, IRD, CNES, CNRS, UPS, \\ 31400 Toulouse, France \\ 4 Environnements et Paléoenvironnements Océaniques et Continentaux (EPOC), UMR 5805, \\ allée Geoffroy St Hilaire, 33615 Pessac CEDEX, France; vincent.marieu@u-bordeaux.fr (V.M.); \\ alexandra.spodar@univ-littoral.fr (A.S); Parisotjp@wanadoo.fr (J.-P.P.); \\ vincent.hanquiez@u-bordeaux.fr (V.H.) \\ 5 Laboratoire d'Océanologie et de Géosciences (LOG), UMR 8187, 59140 Dunkerque, France \\ * Correspondence: edward.salameh@legos.obs-mip.fr; Tel.: +33-6-30-21-26-72
}

Received: 21 December 2017; Accepted: 10 February 2018; Published: 14 February 2018

\begin{abstract}
Radar altimetry was initially designed to measure the marine geoid. Thanks to the improvement in the orbit determination from the meter to the centimeter level, this technique has been providing accurate measurements of the sea surface topography over the open ocean since the launch of Topex/Poseidon in 1992. In spite of a decrease in the performance over land and coastal areas, it is now commonly used over these surfaces. This study presents a semi-automatic method that allows us to discriminate between acquisitions performed at high tides and low tides. The performances of four radar altimetry missions (ERS-2, ENVISAT, SARAL, and CryoSat-2) were analyzed for the retrieval of sea surface height and, for the very first time, of the intertidal zone topography in a coastal lagoon. The study area is the Arcachon Bay located in the Bay of Biscay. The sea level variability of the Arcachon Bay is characterized by a standard deviation of $1.05 \mathrm{~m}$ for the records used in this study (2001-2017). Sea surface heights are very well retrieved for SARAL $(\mathrm{R} \sim 0.99$ and RMSE $<0.23 \mathrm{~m})$ and CryoSat-2 $(\mathrm{R}>0.93$ and RMSE $<0.42 \mathrm{~m})$ missions but also for ENVISAT ( $>0.82$ but with a higher RMSE $>0.92 \mathrm{~m}$ ). For the topography of the intertidal zone, very good estimates were also obtained using SARAL ( $\mathrm{R} \sim 0.71)$ and CryoSat-2 (R 0.79) with RMSE lower than $0.44 \mathrm{~m}$ for both missions.
\end{abstract}

Keywords: radar altimetry; coastal altimetry; sea surface height; topography of the intertidal zone; ERS-2; ENVISAT; SARAL; CryoSat-2

\section{Introduction}

Coastal regions represent only 5\% of Earth's land area, yet their societal and economical importance are larger than their surface area suggests [1]. The land area within $100 \mathrm{~km}$ from the coast accommodates about $39 \%$ of the global population according to the CIESIN (Center for International Earth Science Information Network) [2]. Coastal systems are experiencing high pressures due to population growth and the overexploitation of their resources. Anthropogenic pressures exacerbated 
by sea level rise and the increase of global temperature lead to a rapid and threatening environmental change of these systems, which requires effective long-term coastal management initiatives.

Common features of coastal systems are coastal lagoons, occupying $13 \%$ of coastal areas worldwide [3]. Coastal lagoons are defined as "inland water bodies, separated from the ocean by a barrier, connected to the ocean by one or more restricted inlets which remain open at least intermittently, and have water depth which seldom exceed a few meters" [4]. They are subject to forcings from rivers, wind stress, tides, precipitation to evaporation balance, and surface heat balance [4]. These ecosystems provide important services and societal benefits (e.g., food provision, recreational, water regulation, etc.); however their subsistence is threatened by global climate change [5]. Understanding the physical dynamics of these systems is of great importance in order to direct the planning and implementation of coastal management strategies in coastal lagoons.

In the need for a better understanding of lagoons' dynamics, satellite radar altimetry measuring the variation of the surface elevation could be a very useful tool providing key information, especially for non-monitored areas. However, using altimetry in coastal regions remains a great challenge due to numerous issues including land contamination in the footprint that impacts the radar echo (or waveform), but also the lower quality of the corrections applied to the distance between the satellite and the surface (or altimeter range) than over open ocean [6]. Despite these shortcomings, recent improvements in processing techniques (e.g., careful recovering of flagged data, applying specialized retracking, improving the correction terms) extended the capabilities of altimeters in coastal areas [7].

This study analyzes the performance of radar altimetry to monitor sea level and to provide, for the very first time, topography of the intertidal zone along the altimeter tracks in the Arcachon Bay, a coastal lagoon situated in the south-west of France. The choice of this lagoon as a case study was motivated by the coverage provided by ERS-2, ENVISAT, SARAL, and CryoSat-2 altimetry missions. Our goal is to assess the evolution of measurement accuracy at Ku-band (ERS-2, ENVISAT) and the benefits of the Ka-band (SARAL) in Low Resolution Mode (LRM). An assessment of instrumental performance was undertaken as well for observations made by the Ku-band satellite mission CryoSat-2, the first altimeter to operate in Synthetic Aperture Radar (SAR) mode.

The aim of this study is threefold: (i) to investigate the limitations and potential improvements of altimetry to monitor lagoons Sea Surface Height (SSH), (ii) to test the capability of altimetry to retrieve topographic variations and (iii) to optimize (time wise and accuracy wise) the processing of altimetry data in coastal lagoons environment. Tide gauge measurements and lidar topography datasets were used to evaluate SSHs and topography estimation made by satellite radar altimetry.

\section{Study Area}

The Arcachon Bay $\left(44^{\circ} 40^{\prime} \mathrm{N}, 1^{\circ} 10^{\prime} \mathrm{W}\right)$ is a mesotidal shallow semi-confined lagoon, located in the southeast of the Bay of Biscay (Figure 1). The total lagoon surface $\left(174 \mathrm{~km}^{2}\right)$ is composed of channels $\left(57 \mathrm{~km}^{2}\right)$ that drain the intertidal area $\left(117 \mathrm{~km}^{2}\right)$. The main channels have a maximum depth around $20 \mathrm{~m}$ and are extended by a complex network of secondary channels [8]. The tidal cycle is semi-diurnal with a weak diurnal inequality. The tide amplitudes vary from 0.8 to $4.6 \mathrm{~m}$ for neap and spring tides respectively. The Arcachon Bay connects to the Atlantic Ocean through two narrow passes of 1-1.5 km width and around $12 \mathrm{~km}$ long. The two passes are separated by the Arguin Bank. Important seawater exchanges, reaching up to $384.106 \mathrm{~m}^{3}$ occur during each tidal cycle [9]. Freshwater inputs from small rivers and groundwater are coming mostly from the Eyre River and the Porges Canal, located south-east and north of the Bay respectively (see Figure 1). They represent more than $95 \%$ ( $73 \%$ and $24 \%$ respectively) of the total annual freshwater inflows [10]. The intertidal area is composed of a mix of muddy and sandy material [8]. A large zone of $70 \mathrm{~km}^{2}$ of the mudflats in the inner lagoon is covered with Zostera noltii seagrass [11]. 

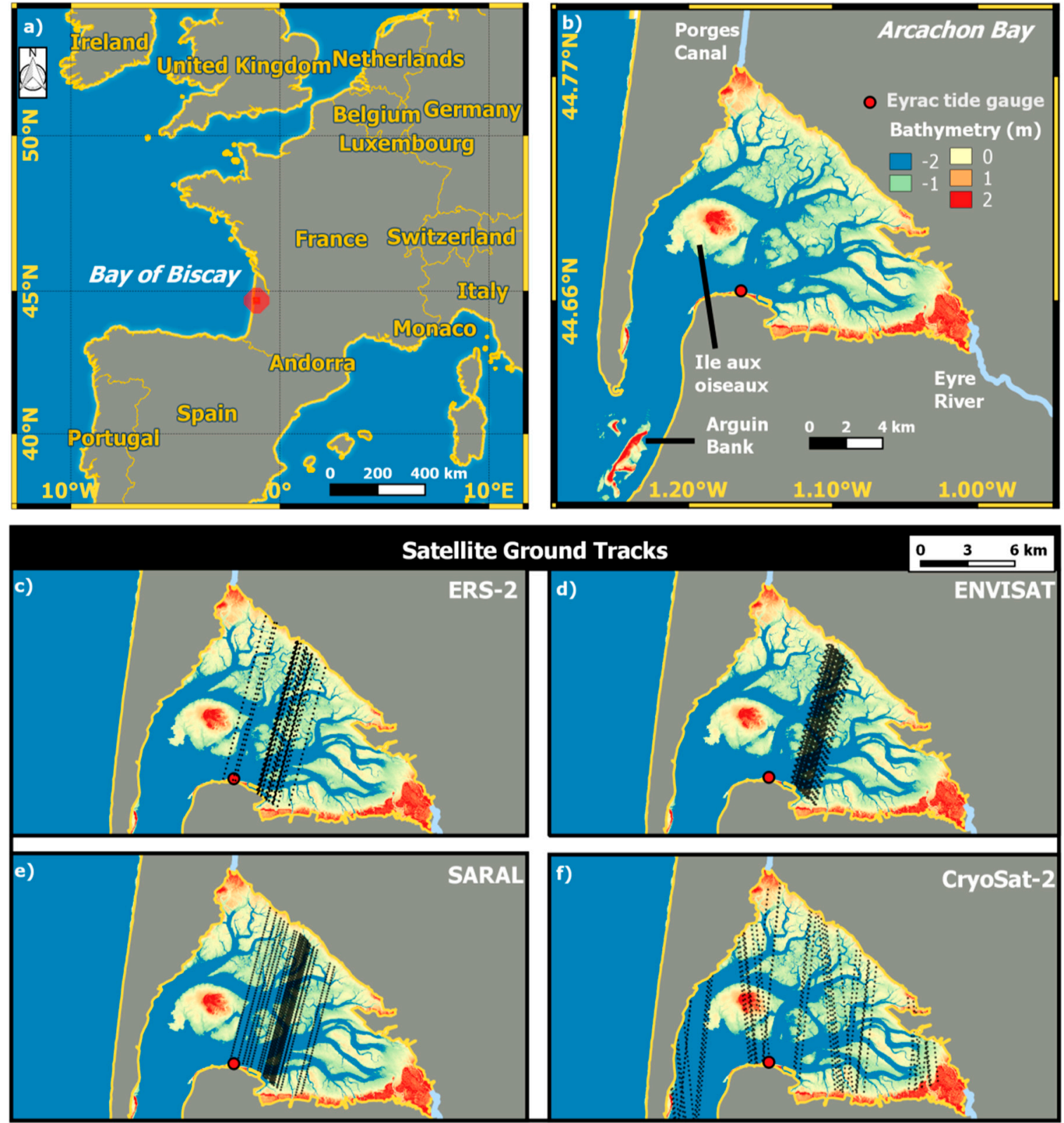

Figure 1. (a) The Arcachon lagoon is located in the Bay of Biscay along the south part of the French Atlantic coast. (b) The Arcachon lagoon is a mesotidal shallow semi-confined lagoon. Several altimetry missions' ground-tracks cover the lagoon: (c) ERS-2 (1993-2003, since 2003 ERS-2 has experienced a number of failures), (d) ENVISAT (2002-2010 on the nominal orbit), (e) SARAL (2013-2016 on the nominal orbit), and (f) CryoSat-2 (since 2010).

\section{Datasets}

\subsection{Altimetry Data}

Table 1 presents a summary of the main characteristics of the altimetry missions used in this study, which are described in more detail below. 
Table 1. Main characteristics of the altimetry missions used in this study.

\begin{tabular}{ccccc}
\hline Mission & ERS-2 & ENVISAT & SARAL & CryoSat-2 \\
\hline Agency & ESA & ESA & CNES/ISRO & ESA \\
Launch on & $21 / 04 / 1995$ & $01 / 03 / 2002$ & $25 / 02 / 2013$ & $08 / 04 / 2010$ \\
End date & $06 / 07 / 2011$ & $08 / 06 / 2012$ & Present & Present \\
Altimeter name & RA & RA-2 & AltiKa & SIRAL \\
Radar frequency & Ku-band & Ku and S-bands & Ka-band & Ku-band \\
Altitude & $785 \mathrm{~km}$ & $790 \mathrm{~km}$ & $790 \mathrm{~km}$ & $717 \mathrm{~km}$ \\
Orbit inclination & $98.52^{\circ}$ & $98.54^{\circ}$ & $98.54^{\circ}$ & $92^{\circ}$ \\
Repetitivity & $35 \mathrm{days}$ & $35 \mathrm{days}$ & $35 \mathrm{days}$ & 369 days \\
Ground-track spacing at the equator & $85 \mathrm{~km}$ & $85 \mathrm{~km}$ & $85 \mathrm{~km}$ & $7.5 \mathrm{~km}$ \\
Along track sampling & $20 \mathrm{~Hz}(350 \mathrm{~m})$ & $18 \mathrm{~Hz}(\sim 400 \mathrm{~m})$ & $40 \mathrm{~Hz}(175 \mathrm{~m})$ & $20 \mathrm{~Hz}(350 \mathrm{~m})$ \\
\hline
\end{tabular}

\subsubsection{ERS-2}

The ERS-2 satellite (European Remote Sensing-2) was launched in 1995 by ESA (European Space Agency). Its payload is composed of several sensors, including a radar altimeter (RA), operating at Ku-band (13.8 GHz). It was sun-synchronously orbiting at an altitude of $785 \mathrm{~km}$ with an inclination of $98.52^{\circ}$ with a 35-day repeat cycle. This orbit has a ground-track spacing about $85 \mathrm{~km}$ at the equator. ERS-2 provided observations of the topography of the Earth from $82.4^{\circ}$ latitude north to $82.4^{\circ}$ latitude south. ERS-2 data are available from 17 May 1995 to 9 August 2010 but with a limited coverage after 22 June 2003.

\subsubsection{ENVISAT}

ENVISAT (ENVIronmental SATellite) mission was launched on 1st March 2002 by ESA. It carries 10 instruments including the advanced radar altimeter (RA-2). RA-2 is a nadir-looking pulse-limited radar altimeter operating at two frequencies at $\mathrm{Ku}-(13.575 \mathrm{GHz})$ and S- $(3.2 \mathrm{GHz})$ bands. ENVISAT orbits at an altitude of $790 \mathrm{~km}$, with an inclination of $98.54^{\circ}$, on a sun-synchronous orbit with a 35-day repeat cycle, providing observations of the Earth surface (ocean and land) from $82.4^{\circ}$ latitude North to $82.4^{\circ}$ latitude South. This orbit was formerly used by ERS-1 and 2, with an equatorial ground-track spacing of about $85 \mathrm{~km}$. ENVISAT remains on its nominal orbit until October 2010 [12]. From November 2010 to April 2012, ENVISAT was put into the extending phase consisting of a drifting on a 30-day orbit lowered by $17 \mathrm{~km}$.

\subsubsection{SARAL}

SARAL (Satellite for Argos and ALtika) is a CNES-ISRO (Centre National d'Etudes Spatiales-Indian Space Research Organization) joint-mission that was launched on 25 February 2013. Its payload is composed of the AltiKa radar altimeter and bi-frequency radiometer, and a triple system for precise orbit determination: the real-time tracking system DIODE of DORIS instrument, a Laser Retroflector Array (LRA), and the Advanced Research and Global Observation Satellite (ARGOS-3). Its orbital characteristics are the same as ENVISAT (see above). The first four cycles of SARAL do not follow precisely the ENVISAT orbit. AltiKa radar altimeter is a solid-state mono-frequency altimeter that provides accurate range measurements. It is the first altimeter to operate at Ka-band ( $35.7 \mathrm{GHz})$. Its accuracy is expected to be about $1 \mathrm{~cm}$ over ocean. Over the coastal regions, it is expected to provide measurements significantly better than those from the previous Ku band missions. Improvements come from the reduced footprint of the Ka-band (about ten times smaller in surface than it is in Ku-band) and from the higher along-track sampling rate of $40 \mathrm{~Hz}(\sim 175 \mathrm{~km})$, twice that of ENVISAT [13].

\subsubsection{CryoSat-2}

CryoSat- 2 mission was launched on 8 April 2010 by ESA. This mission is dedicated mainly to polar observations. However, its acquisitions can be useful for ocean and inland monitoring as it provides a global monitoring of the Earth's surface [14]. The mission's main payload consists of a radar altimeter, SIRAL (Synthetic Aperture Interferometric Radar Altimeter), operating at Ku-band 
$(13.575 \mathrm{GHz})$ in three different modes: Low Resolution Mode (LRM), Synthetic Aperture Radar mode (SAR), and Synthetic Aperture Interferometric mode (SARIn). CryoSat-2 orbits at an altitude of $717 \mathrm{~km}$, with an inclination of $92^{\circ}$, on a non-sun-synchronous orbit with a 369-day repeat cycle. The equatorial ground-track spacing is about $7.5 \mathrm{~km}$ shifting every 30 days. The short inter-track distance increases the sampling over the study area during one cycle [15]. For this study region and period, CryoSat-2 operated in SAR mode.

All altimetry data used in this study come from the Geophysical Data Records (GDR) made available by the Centre of Topography of the Oceans and the Hydrosphere (CTOH-http:/ / ctoh.legos. obs-mip.fr /). They are sampled along the altimeter track at $18 \mathrm{~Hz}$ for ENVISAT, $20 \mathrm{~Hz}$ for ERS-2 and CryoSat-2, and $40 \mathrm{~Hz}$ for SARAL (high-frequency mode commonly used over land and coastal areas where the surface properties are changing more rapidly than over the open ocean).

\subsection{Ancillary Data}

\subsubsection{Arcachon-Eyrac Tide Gauge}

The Arcachon-Eyrac tide gauge is managed by the French hydrographic service (Service Hydrographique et Océanographique de la Marine-SHOM) and the Gironde sea and land state office (Direction Départementale des Territoires et de la Mer-DDTM). It is operating since November 1967 . The tide gauge (Figure 1) $\left(1.163550021^{\circ} \mathrm{W}\right.$ and $\left.44.66500092^{\circ} \mathrm{N}\right)$ is a non-contact radar sensor providing sea level measurements at 1-min time intervals since June 2000 . These data are made available by REFMAR (available online: http:/ / refmar.shom.fr/, accessed on 10 February 2018). Altimetry and tide gauge data timeline is shown in Figure 2.

\section{Data Timeline}

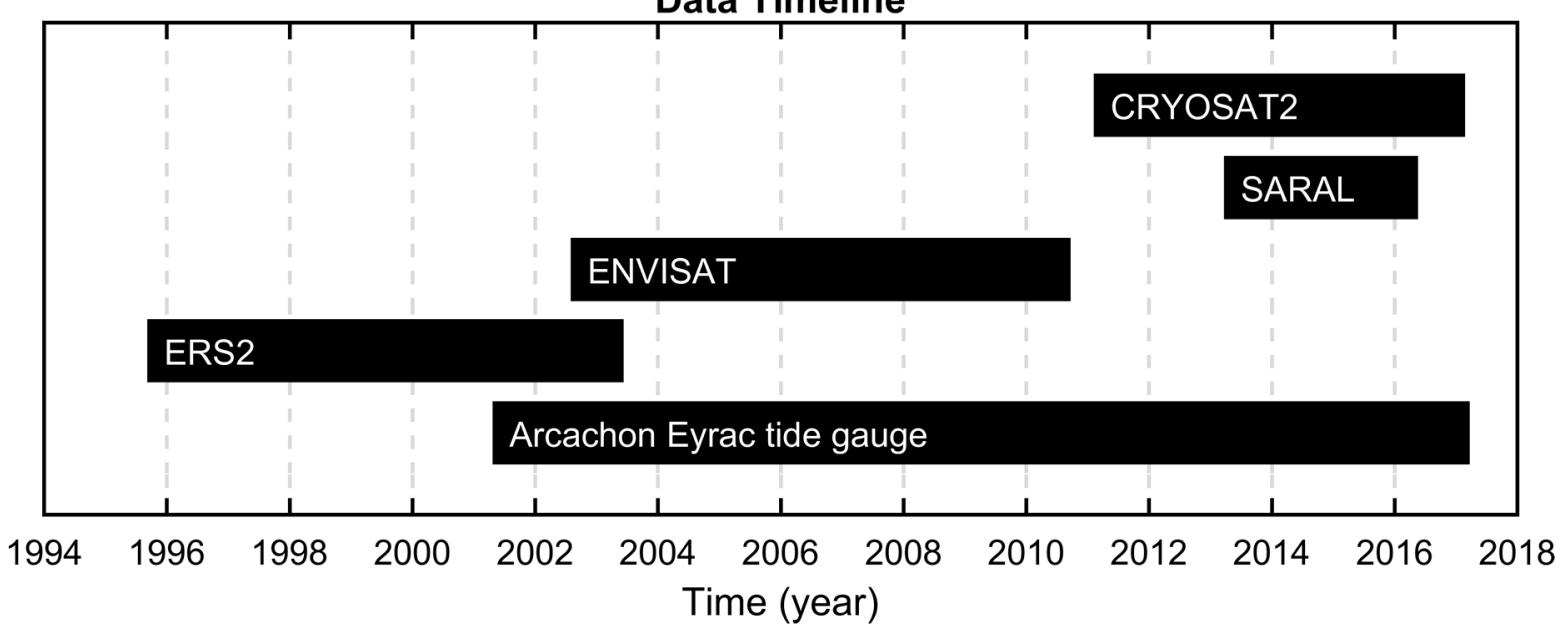

Figure 2. Temporal coverage of the in situ Arcachon Eyrac tide gauge and altimetry datasets used in this study.

\subsubsection{Lidar-Derived Topography of the Intertidal Zone}

The LIDAR data is extracted from RGE ALTI ${ }^{\circledR}$ product provided by the French national institute for geography and forest information (IGN). Arcachon Bay raw data have been acquired by airborne topographic LIDAR at low tide, on 25 June 2013, and interpolated on a regular $1 \times 1 \mathrm{~m}$ grid for RGE $\mathrm{ALTI}^{\circledR}$ product. The controlled altimetric precision for this data is $0.2 \mathrm{~m}$. For the convenience of the study, these data have been subsampled on a $10 \times 10 \mathrm{~m}$ grid.

\section{Methods}

The following flowchart exhibits the different steps of the methodology (Figure 3). All steps are described in the corresponding sections. 


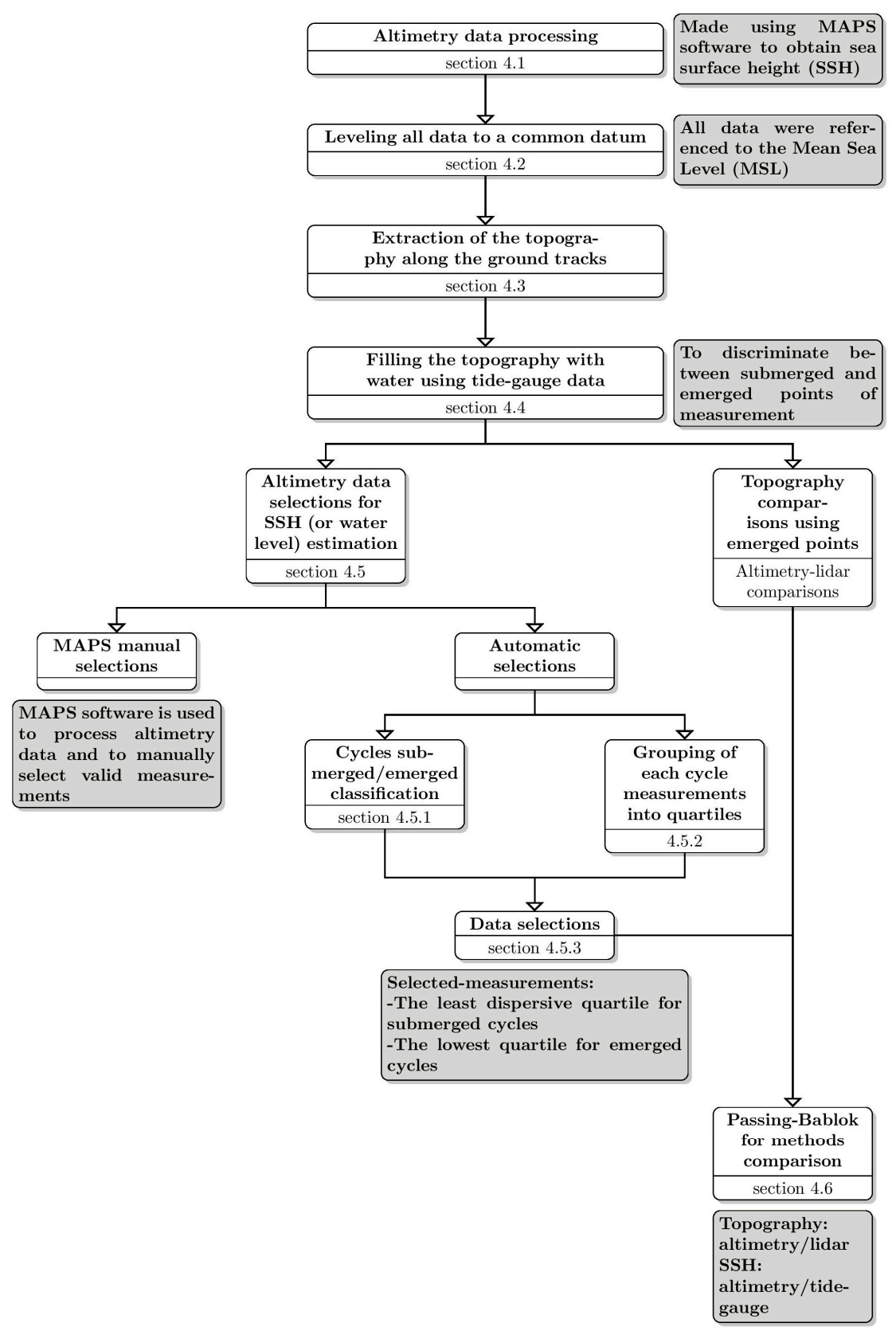

Figure 3. The different steps of the method presented in the form of a flow chart.

\subsection{Altimetry Data Processing}

The principle of radar altimetry is the following: the altimeter emits a radar pulse and measures the two-way travel-time from the satellite to the surface. The distance between the satellite and the Earth surface - the altimeter range $(R)$ - is thus derived with a precision of a few centimeters. The satellite altitude $(H)$ referred to an ellipsoid is also accurately known from orbitography modeling. Taking into account propagation delays due to interactions of electromagnetic wave in the atmosphere and geophysical corrections, the height of the reflecting surface $(h)$ with reference to an ellipsoid or a geoid can be estimated as [16,17]:

$$
h=H-\left(R+\sum \Delta R_{\text {propagation }}+\sum \Delta R_{\text {geophysical }}\right)
$$


where $H$ is the height of the center of mass of the satellite above the ellipsoid, $R$ is the nadir altimeter range from the center of mass of the satellite to the sea surface taking into account instrumental corrections, $\Delta R_{\text {propagation }}$ and $\Delta R_{\text {geophysical }}$ are the sums of the environmental and geophysical corrections to apply to the range and respectively given by Equations (2) and (3).

$$
\sum \Delta R_{\text {propagation }}=\Delta R_{\text {ion }}+\Delta R_{\text {dry }}+\Delta R_{\text {wet }}+\Delta R_{S S B}
$$

$\Delta R_{i o n}$ is the atmospheric refraction range delay due to the free electron content associated with the dielectric properties of the ionosphere, $\Delta R_{d r y}$ is the atmospheric refraction range delay due to the dry gas component of the troposphere, $\Delta R_{\text {wet }}$ is the atmospheric refraction range delay due to the water vapor and the cloud liquid water content of the troposphere, $\Delta R_{S S B}$ is the range correction due to the interaction of the electromagnetic pulse emitted by the altimeter with the scatterometers within the footprint. It is known as Sea State Bias (SSB) and is the sum of the electromagnetic (EM), skewness, and tracker biases.

$$
\sum \Delta R_{\text {geophysical }}=\Delta R_{\text {ocean }}+\Delta R_{\text {solid Earth }}+\Delta R_{\text {pole }}+\Delta R_{\text {atm }}
$$

where $\Delta R_{\text {ocean }}$ is the value of the ocean tide, $\Delta R_{\text {solid Earth }}$ and $\Delta R_{\text {pole }}$ are the corrections respectively accounting for crustal vertical motions due to the solid Earth and polar tides, $\Delta R_{a t m}$ is the dynamic atmosphere correction.

Altimetry-derived heights are automatically obtained from the GDR data using the Multi-mission Altimetry Processing Software (MAPS) that is commonly used for the selection of valid altimetry data and their processing over land and ocean [18-20]. More details on MAPS can be found in Frappart et al. [21]. As the $\Delta R_{S S B}$ values were most of the times flagged in the GDR, they were not applied for the consistency of the series of observations. $\Delta R_{S S B}$ corresponds to cm-level correction applied to the range as it varies typically from $-1 \%$ to $4 \%$ of the Significant Wave Height (SWH) (e.g., Gaspar et al. [22]). In the Arcachon Bay, SWH is generally lower than $0.2 \mathrm{~m}$ but can exceptionally reach 0.5 to $0.7 \mathrm{~m}$ for wind intensities greater than $20 \mathrm{~m} \cdot \mathrm{s}^{-1}$ [23]. $\Delta R_{\text {ocean }}$ and $\Delta R_{\text {atm }}$ were not applied as they also affect the measurements from the Arcachon-Eyrac tide-gauge. Due to the width of the altimeters and radiometers footprints of several kilometers and several tenths of kilometers, radar echoes are a mix of returns from ocean, intertidal zone, and from the surrounding environment (forests, cities, roads, etc.) and microwave brightness temperatures are the combination of emissions from a very inhomogeneous environment. The same set of corrections used for land hydrology will be applied in this study.

The geophysical corrections applied to the range are derived from the Global Ionospheric Maps (GIM) and Era Interim model outputs from the European Centre Medium-Range Weather Forecasts (ECMWF) for the ionosphere and the dry and wet troposphere range delays respectively. The environmental corrections are obtained from the solid Earth tide [24] and polar tide [25] tables for SARAL, and using the IERS (International Earth Rotation and Reference Systems) convention for ENVISAT. Ranges used to derive altimeter heights were those processed with the Ice-1 retracking algorithm [26,27] (formulation in Appendix A) because they are present in the ERS-2, ENVISAT and SARAL GDRs and were shown to be more suitable for hydrological studies in terms of accuracy of water levels and availability of the data (e.g., Frappart et al. [28,29]). For CryoSat-2, altimeter heights were those processed by the Sea-Ice retracker [30].

\subsection{Leveling to a Common Datum}

The datasets used in this study are referenced to various datums. ENVISAT and CryoSat-2 altimetry data are referenced to WGS84 ellipsoid, SARAL altimetry data to the Topex/Poseidon (T/P) ellipsoid, the lidar-based topography of the intertidal zone to the French reference system NGF/IGN69, and the Arcachon-Eyrac tide-gauge to the French chart datum. A datum conversion from T/P ellipsoid 
to WGS84 is automatically performed for SARAL measurements using Equation (4) adapted from [31] in the new version of MAPS implemented for this study:

$$
\Delta h=\frac{a^{\prime}\left(1-e^{\prime 2}\right)}{\sqrt{1-e^{\prime 2} \sin ^{2} \varphi}}-\frac{a\left(1-e^{2}\right)}{\sqrt{1-e^{2} \sin ^{2} \varphi}}
$$

where $\Delta h$ is the variation of height at latitude $\varphi$ due to the change of ellipsoid from T/P to WGS84 datum, $a=6,378,137 \mathrm{~m}$ and $e=0.081819190842621$ are the semi-major axis and the eccentricity of the WGS84 datum, $a^{\prime}=6,378,136.3 \mathrm{~m}$ and $e^{\prime}=0.081819221456$ are the semi-major axis and the eccentricity of the $\mathrm{T} / \mathrm{P}$ datum.

For comparison purposes, they were all referenced to the Mean Sea Level (MSL). Datum conversion for all data (altimetry, topography, and tide gauge data) were made using the French maritime altimetry references [32] giving the vertical differences between the different datum ( $-44.8 \mathrm{~m}$ between WGS84 and the French chart, $-1.98 \mathrm{~m}$ between the French chart and the French reference system, and $-2.48 \mathrm{~m}$ between the French chart and the MSL).

\subsection{Extraction of the Topography of the Intertidal Zone under the Altimeter Tracks}

For comparison purposes, the topography of the intertidal zone was extracted along the altimeter ground tracks. For each altimetry measurement, the closest topography point was selected. The maximum distance obtained between an altimetry measurement and its corresponding topography point is $10 \mathrm{~m}$, which is consistent with the spatial resolution of the lidar-derived topography $(10 \mathrm{~m})$. This extraction was performed for every ERS-2, ENVISAT, SARAL, and CryoSat-2 cycle as the orbit of the satellites is not exactly repetitive and generally varies within $1 \mathrm{~km}$ around the nominal track (Figure 1).

\subsection{Manual Classifications of Altimetry Measurements and Cycles}

Two types of classification based on ancillary data were made. The first one consists of separating altimetry measurements between submerged and emerged measurement points. This classification was made in order to use submerged points for SSH estimation, and emerged points for topography measurements. The resulting altimetry levels were compared to Arcachon Eyrac in-situ gauge measurements and lidar topography data respectively. To discriminate between land and water, the topography along the altimeter tracks is filled with the water levels measured at the Arcachon-Eyrac tide gauge. For each gridpoint of the Lidar-based topography, the gridpoint is considered submerged if the water level is greater than the topography, emerged if not (see Figures 6 and 7 in Section 5).

The second type is a classification by cycle and it was made to separate cycles with emerged land from completely submerged cycles. The cycle is considered as an emerged cycle if more than $20 \%$ of the altimeter ground track flew over land. This classification was performed to assess the performance of the automatic classification presented in Section 4.5.1.

\subsection{Automatic Selections of Valid Altimetry Measurements}

A method to automatically select the altimetry measurements (used for SSH estimation) over emerged and submerged areas was tested. It is composed of the following steps.

\subsubsection{Classification of Cycles between Submerged and Emerged Cycles}

This first step discriminates submerged from emerged cycles using intrinsic altimetry parameters in order to be completely independent of in-situ data. The rationale behind this step is the use of different selection criteria for submerged and emerged cycles. The classification was made using the unsupervised $\mathrm{k}$-means clustering algorithm [33]. The number of clusters $(\mathrm{k})$ was chosen to be two for submerged and emerged classes and the distance measure technique used is the cityblock (Manhattan) technique [34]. In contrast to the Euclidean distance (straight line distance between two points in Euclidean space), the cityblock distance is calculated as the distance in $\mathrm{x}$ plus the 
distance in y (in 2D). The backscattering coefficient and the peakiness (the average of these parameters per cycle) are the two parameters used to perform the clustering technique (peakiness formulation can be found in Appendix A). Before data clustering, the latter parameters were normalized and centered in order to unify their influence on distance. The use of these two parameters is based on a priori knowledge that they present significant descrepancies between water-dominated footprints and water-land-mixed footprints.

\subsubsection{Grouping of Cycle's Measurements into Four Equal Parts}

In this step, the altimetry measurements made during a given cycle were separated into four equally-sized groups. The four groups were separated by the following scores: Quartile 0 (the minimum), Quartile 1 (larger than $25 \%$ of the data points), Quartile 2 (the median), Quartile 3 (bigger than $75 \%$ of the data points), and Quartile 4 (the maximum). For each group, the standard deviation is computed to assess its dispersion.

\subsubsection{Data Automatic Selections}

For cycles classified as submerged cycles, the groups with the least standard deviation (least dispersion) are preserved. For cycles classified as emerged cycles, the first groups with the lowest $25 \%$ of values (values between Quartile 0 and Quartile 1 ) are preserved because these groups are the only groups able to reach the water when land emerges.

The results of the two types of selections are compared in Section 5.2.

\subsection{Passing-Bablok Regression for Method Comparisons}

Passing-Bablok is the regression method used to account for agreement and systematic bias between two methods (altimetry/tide-gauges or altimetry/lidar). We opted for Passing-Bablok method instead of ordinary linear regression because it is not sensitive to the outliers or the distribution of errors and because the independent variable (water level from tide gauge records or bathymetry from lidar) is not free of error. This robust, non-parametric method consists of fitting a line describing the relationship between the two variables ( $\mathrm{X}$ and $\mathrm{Y}$ ) and testing whether the slope is 1 and the intercept is 0 . In-depth details on the method can be found in [35]. The results are presented as a scatter plot between $X(\operatorname{method} 1)$ and $Y($ method 2$)$, a regression line, and a linear regression equation where the slope and the intercept represent proportional and constant systematic bias respectively. A statistical test of the assumption of linearity is performed using cumulative sum linearity test. Non-linear samples are not suitable for concluding on method agreement. Furthermore, a 95\% Confidence Interval (CI) is also computed for the slope and the intercept to test the hypothesis that the slope is equal to 1 or the intercept is equal to 0 . These hypotheses are accepted if 1 corresponds to the slope's $95 \%$ CI (if not, there is a proportional difference between the two methods) and if 0 corresponds to the intercept's $95 \%$ $\mathrm{CI}$ (if not, there is a constant difference or bias between the two methods).

\subsection{Absolute Calibration of Altimetry Missions over the Intertidal Zone}

Comparisons between altimetry-based and in situ SSH from tide gauge were performed. They require simultaneous in situ and altimetry measurements in the same terrestrial reference frame at the exact same location or comparison point (e.g., Cancet et al. [36]). The absolute altimeter bias (Bias altimeter $)$ is estimated as follows [37]:

$$
\text { Bias altimeter }=<h_{\text {altimeter }}-h_{\text {in situ }}>
$$

where $h_{\text {altimeter }}$ and $h_{\text {in situ }}$ are the height of the reflecting surface estimated from altimeter and in situ measurements respectively. In this study, an absolute calibration is performed for estimating the bias of ERS-2, ENVISAT, SARAL and CryoSat-2 for sea level measurements and topography of the intertidal zone in the Arcachon Bay. 


\section{Results}

Depending on their overflight time, radar altimetry missions acquired observations of the Arcachon Bay all over the tidal cycle. During low tide, they provide observations of the surface topography of the intertidal zone whereas, at high tides, they monitor the sea surface height. These changes in the nature of the reflecting surface, from wet sand and mud to sea water, modify the radar echo acquired by the altimeter. Lidar-based topography profiles were extracted along the altimetry ground tracks in the intertidal zone of the Arcachon Bay. They were filled with water using the record from Arcachon-Eyrac tide-gauge corresponding to the altimeter overflights. They were compared to the along track profiles of altimeter height, backscattering coefficients and waveform peakiness (not available for ERS-2 in the CTOH GDR and only available at $1 \mathrm{~Hz}$ for ENVISAT) estimated using the Ice-1 retracking algorithm for ERS-2, ENVISAT and SARAL and the SeaIce retracking algorithm for CryoSat-2 (see [27]) for details about the computation of these two latter parameters that are available in the altimeter GDRs). Examples for high and low tides using SARAL and CryoSat-2 data are respectively presented in Figures 4 and 5 (same type of figures is available in the Supplementary Material for ERS-2 (Figure S1) and ENVISAT (Figure S2)). SSH estimated using altimetry data was given by the median of submerged points' altimeter heights. For high and low tides, SARAL and CryoSat-2 missions show relatively good correspondence with in situ measurements while ERS-2 and ENVISAT show low accuracy, especially at low tides. ERS-2 is unable to accurately retrieve topography variations due to both, the coarse resolution of its footprint and changes in the range resolution between ocean (bandwidth of $300 \mathrm{MHz}$ ) and ice modes (bandwidth of $20 \mathrm{MHz}$ ). As for ENVISAT, despite the important bias obtained, altimetry measurements follow the topography variations and give an acceptable correlation coefficient as a result (see Sections 5.2 and 5.3). We observe a significant increase in the backscattering coefficients and waveform peakiness values between high and low tide (Figure 4c,d, and Figure 5c,d). This is due to the contribution of the emerging land to the received signal. A slight variation of these parameters is observed as well at the extreme sides for high tides where land and water fall together in the altimeter footprint.
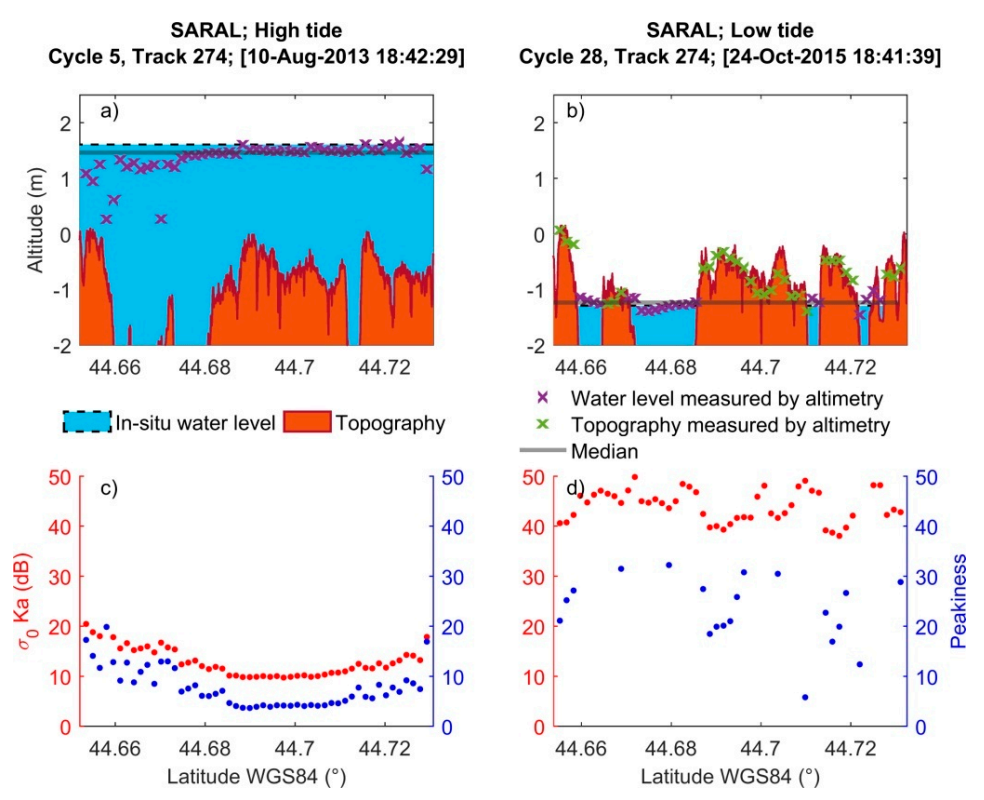

Figure 4. (a,b) Examples of SARAL along-track profiles of altimetry height over water (purple crosses) and land (green crosses) at high (a) and low (b) tides, the topography under the altimeter ground track is represented in brown and it is filled with water (in blue) using leveled tide-gauge records; (c,d) Variation of Ice-1 backscattering coefficients of Ka-band (red dots) and Peakiness (blue dots) at high (c) and low (d) tides. 
CRYOSAT2; High tide Cycle 7, Track 3015; [17-May-2016 15:20:27]

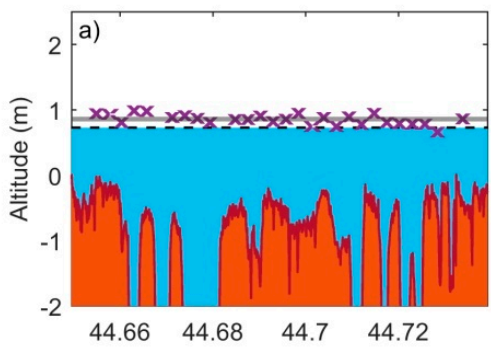

i.--In-situ water level $\square$ Topography

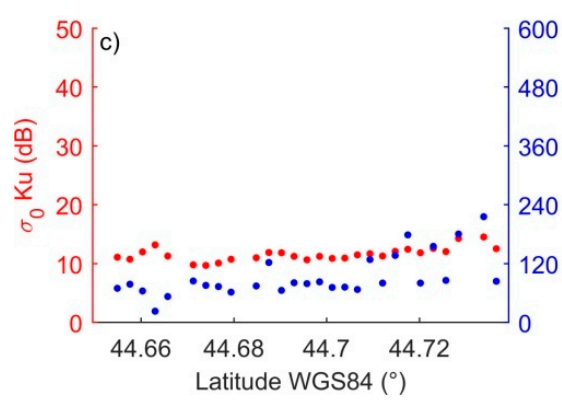

CRYOSAT2; Low tide

Cycle 3, Track 6564; [04-Sep-2012 22:34:32]

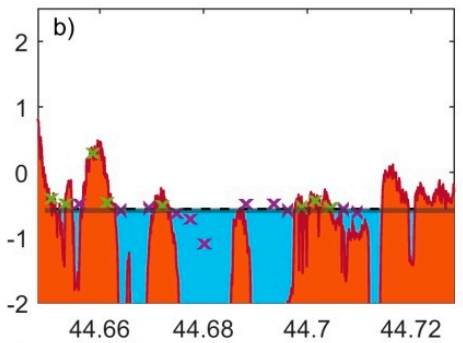

$\times$ Water level measured by altimetry

$x$ Topography measured by altimetry

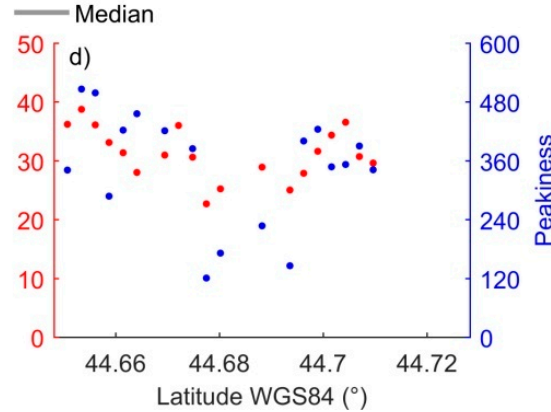

Figure 5. (a,b) Examples of CryoSat-2 along-track profiles of altimetry height over water (purple crosses) and land (green crosses) at high (a) and low (b) tides, the topography under the altimeter ground track is represented in brown and it is filled with water (in blue) using leveled tide-gauge records; (c,d) Variation of Retracker 1 backscattering coefficients of Ku-band (red dots) and Peakiness (blue dots) at high (c) and low (d) tides.

\subsection{Auto-Classification Using the k-Means Algorithm}

Using the k-means algorithm, the altimetry cycles were classified between emerged and submerged cycles. The evaluation of the auto-classification was made using the classification based on in-situ data as explained in Section 4.4. It should be noted that the clustering technique was made using two parameters (the backscattering coefficient and peakiness) for SARAL and CryoSat-2 (Figure 6), and using only the backscattering coefficient for ERS-2 and ENVISAT. SARAL showed the best classification results with $100 \%$ accordance with manual classification. A good consistency was shown also by CryoSat-2 and ENVISAT with $\sim 80 \%$ accordance and ERS- 2 with $82 \%$.

a) SARAL manual classification

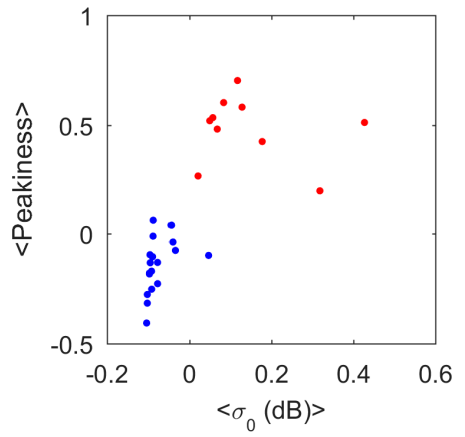

b) SARAL automatic classification

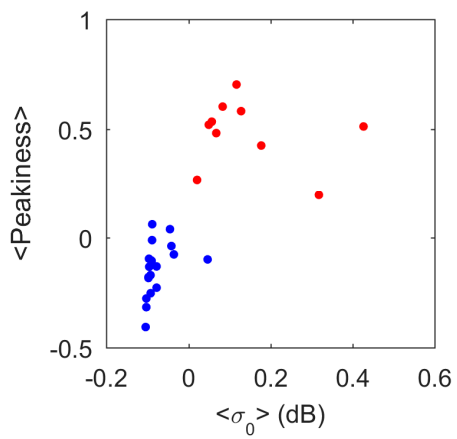

Figure 6. Cont. 
c) CRYOSAT2 manual classification

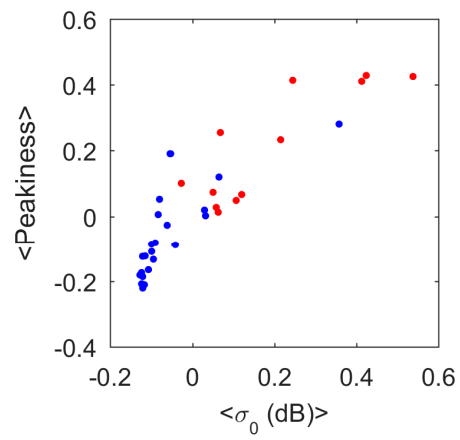

d) CRYOSAT2 automatic classification

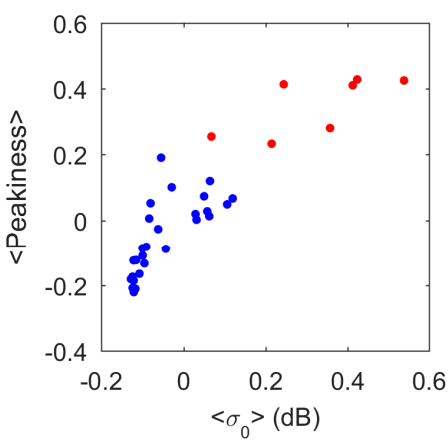

\section{Emerged}

Figure 6. Comparisons between manual (left) and automatic (right) classifications (made using an unsupervised clustering technique) of cycles for SARAL $(\mathbf{a}, \mathbf{b})$ and CryoSat-2 (c,d).

\subsection{Water Levels Comparison}

For the selections made using MAPS, SSH estimation was given by the median of submerged altimetry measurements made during one crossing (cycle). An automatic selection of altimetry data was performed in addition to the manually refined data selections in MAPS. The automatic technique uses the less dispersive quartile of measurements in each cycle for cycles classified as submerged by the clustering technique, and the lowest quartiles for cycles classified as emerged. The SSH was given by the median of the chosen quartile without eliminating measurement points classified as emerged by the classification based on ancillary data. Figure 7 presents the comparisons made between SSHs acquired by altimetry and tide gauge measurements for MAPS manual selections (left) and for automatic selections (right) for ERS-2 ( $a$ and $b$ ), ENVISAT ( $c$ and d), SARAL (e and f), and CryoSat-2 ( $g$ and $h$ ).
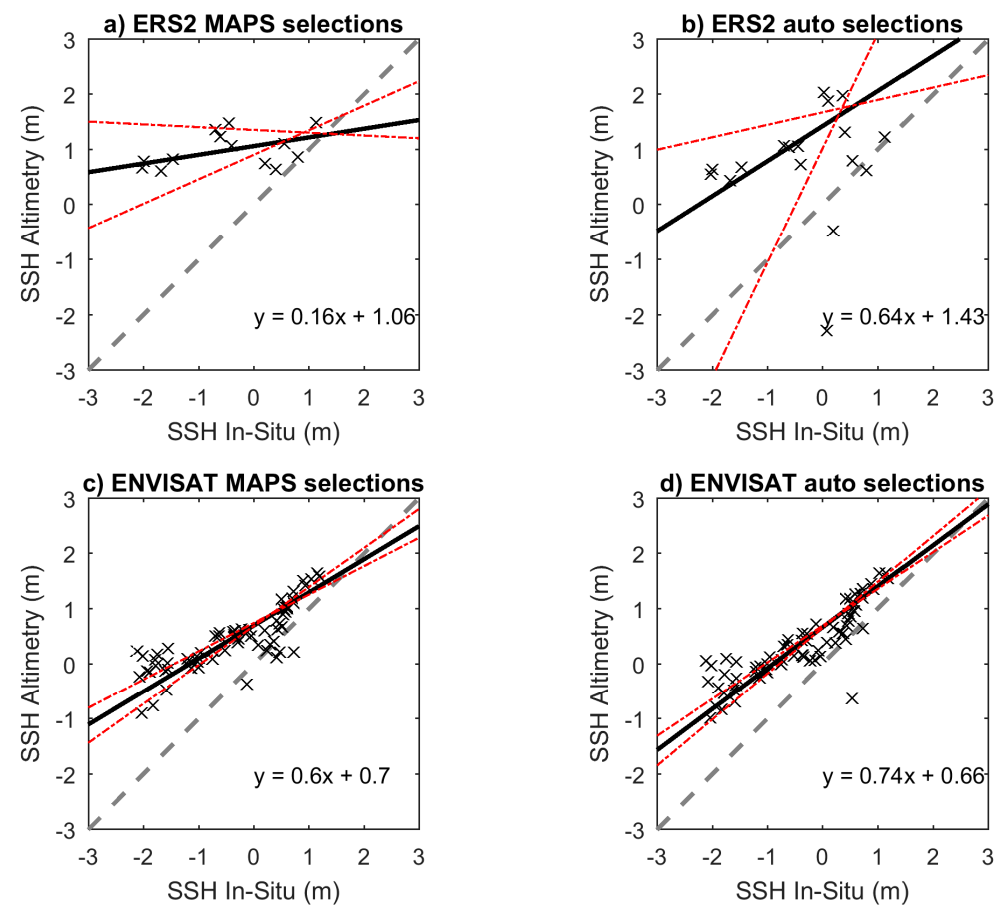

Figure 7. Cont. 

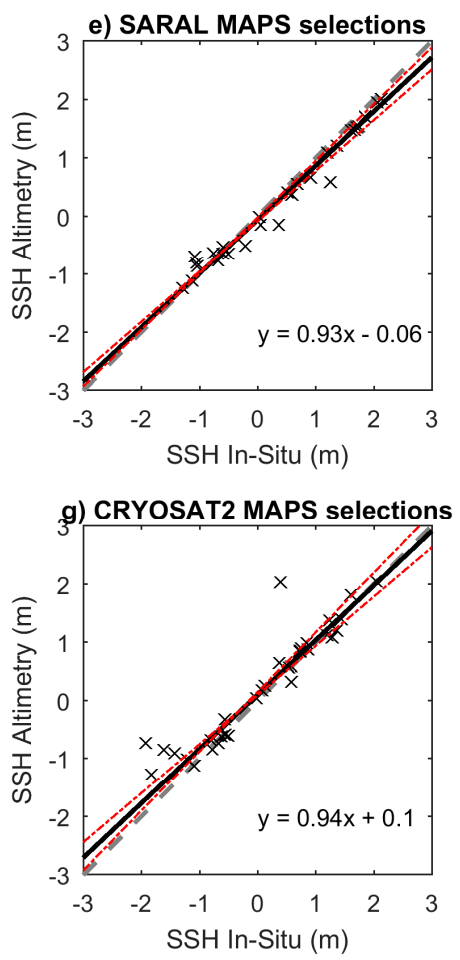

$---y=x-$ Linear regression
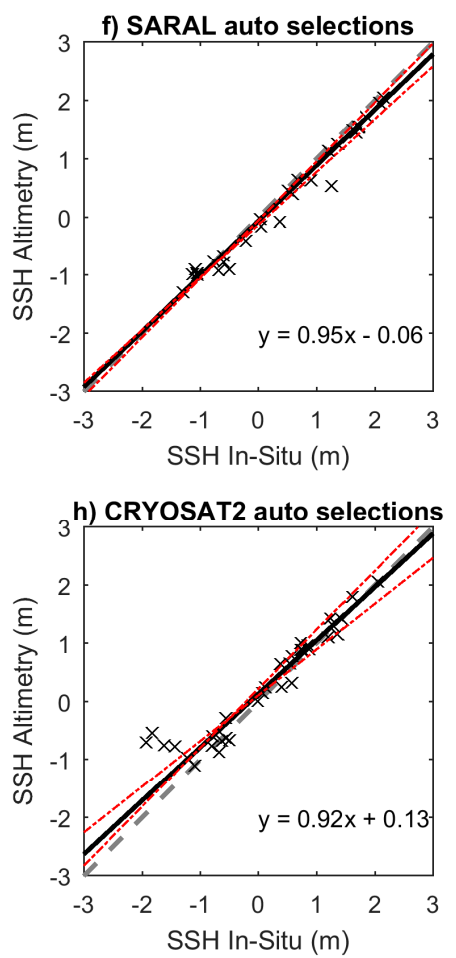

Upper/Lower bounds

Figure 7. Comparisons between in-situ and altimetry-based SSH for ERS-2 (a,b), ENVISAT (c,d), SARAL (e,f), and CryoSat-2 (g,h) using two different approaches for selecting the valid measurements: MAPS manual selections (left) and automatic selections (right).

Linearity exists between altimetry and the tide gauge measurements, for ERS-2, SARAL, and CryoSat-2 data for the two types of selections and for the automatic selections made for ENVISAT (Table 2).

Table 2. Passing-Bablok regression model and statistical results for the comparisons made between in-situ and altimetry-based SSH (ERS-2, ENVISAT, SARAL, and CryoSat-2) for manual (MAPS) and automatic selections.

\begin{tabular}{ccccccccc}
\hline \multirow{2}{*}{ Mission } & \multicolumn{4}{c}{ MAPS } & \multicolumn{5}{c}{ Auto } \\
\cline { 2 - 9 } & ERS-2 & ENVISAT & SARAL & CryoSat-2 & ERS-2 & ENVISAT & SARAL & CryoSat-2 \\
\hline Linearity $^{3}$ & 1 & 0 & 1 & 1 & 1 & 1 & 1 & 1 \\
Slope & 0.16 & 0.60 & 0.93 & 0.94 & 0.64 & 0.74 & 0.95 & 0.92 \\
Slope LB ${ }^{1}$ & -0.05 & 0.51 & 0.87 & 0.85 & 0.23 & 0.67 & 0.91 & 0.79 \\
Slope UB ${ }^{2}$ & 0.44 & 0.71 & 0.97 & 1.02 & 2.07 & 0.83 & 1.01 & 1.01 \\
Intercept & 1.06 & 0.70 & -0.06 & 0.10 & 1.43 & 0.66 & -0.06 & 0.13 \\
Intercept LB & 1.36 & 0.74 & -0.09 & 0.10 & 1.68 & 0.69 & -0.13 & 0.11 \\
Intercept UB & 0.91 & 0.69 & -0.02 & 0.15 & 1.02 & 0.65 & -0.05 & 0.22 \\
R & 0.39 & 0.82 & 0.99 & 0.93 & 0.11 & 0.86 & 0.99 & 0.95 \\
RMSE (m) & 1.75 & 1.04 & 0.23 & 0.42 & 1.70 & 0.92 & 0.22 & 0.39 \\
Mean Bias (m) & 1.47 & 0.88 & 0.18 & 0.23 & 1.50 & 0.79 & 0.17 & 0.24 \\
\hline
\end{tabular}

ERS-2 showed the most unsatisfactory results with slopes lower than 0.64 and intercepts higher than 1 (Table 2). The results obtained by the Passing-Bablok method could not be interpreted for ENVISAT MAPS selections since no linear relationship exists with the tide gauge measurements (a break is observed in the slope at $0 \mathrm{~m}$ (Figure 7c)). Low accuracy for MAPS selections made for ENVISAT could be inferred from the RMSE and the mean bias obtained (1.04 $\mathrm{m}$ and $0.88 \mathrm{~m}$ respectively). The automatic selections significantly improved the estimation of SSH obtained using ENVISAT data 
and rendered the linearity test positive. The slopes given by ENVISAT increased from 0.60 to 0.74 and were accompanied by an improvement of $\mathrm{R}$ (from 0.82 to 0.86 ) and RMSE that remains important (RMSE 0.92 m) (Table 2). As explained in Section 4.6, the method does not show proportional or constant biases if 1 belongs to the slope $\mathrm{CI}$ (slope(LB) $<1<\operatorname{slope}(\mathrm{UB})$ ) and 0 belongs to the intercept $\mathrm{CI}$ (intercept $(\mathrm{LB})<0<$ intercept $(\mathrm{UB})$ ) respectively. For SARAL, a better result is obtained using the automatic selection showing only constant bias with no proportional bias (the confidence interval of the slope contains the value 1). Slight proportional and constant biases are obtained for MAPS selections. MAPS selections present better results for CryoSat-2 that shows slight constant biases with no proportional biases for the two types of selections.

\subsection{Topography Comparison}

Figure 8 presents topography comparisons between lidar and altimetry measurements for ERS-2 (a), ENVISAT (b), SARAL (c), and CryoSat-2 (d). For topography comparisons all measurements from every cycle were used along with the corresponding lidar topography measurements. Table 3 lists all regression models obtained. Linearity was rejected only for ENVISAT data. Therefore, the slope and the intercept obtained for ENVISAT could not be interpreted. Good comparison results are obtained for SARAL giving a slope of 1.06 and an intercept at 0.01 with no proportional or constant bias observed for topography monitoring. CryoSat-2 provides as well acceptable results with slight systematic and proportional biases. Showing a positive linearity test, ERS-2 slope and intercept showed large differences from 1 and 0 .
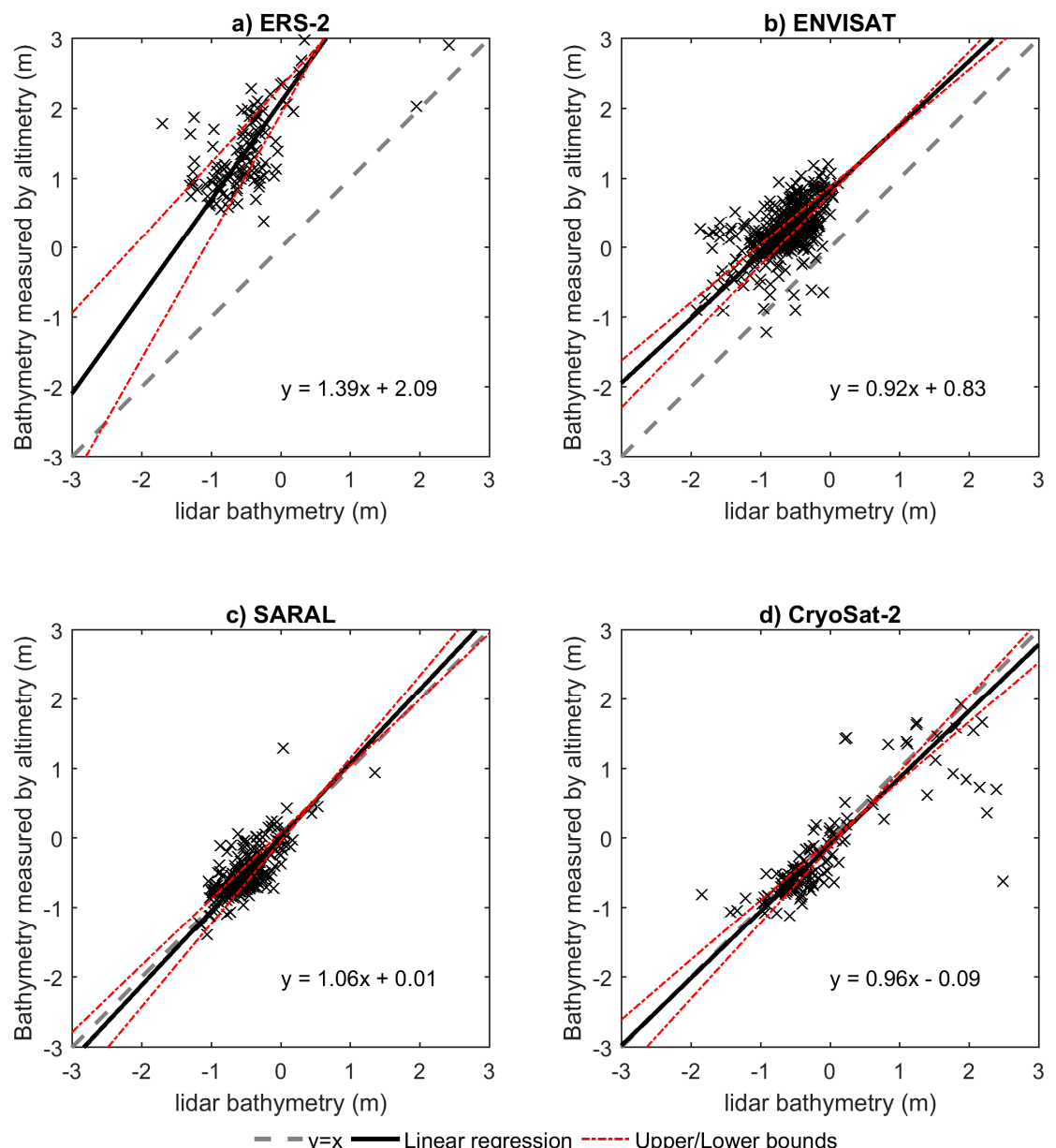

Figure 8. Comparisons between lidar and Altimetry-based topography measurements for: (a) ERS-2, (b) ENVISAT, (c) SARAL, and (d) CryoSat-2. 
Table 3. Passing-Bablok regression model and statistical results for the comparisons made between lidar and altimetry-based topography estimation for ERS-2, ENVISAT, SARAL, and CryoSat-2.

\begin{tabular}{|c|c|c|c|c|}
\hline Mission & ERS-2 & ENVISAT & SARAL & CryoSat-2 \\
\hline Linearity Test $^{3}$ & 1 & 0 & 1 & 1 \\
\hline Slope & 1.39 & 0.92 & 1.06 & 0.96 \\
\hline Slope LB ${ }^{1}$ & 1.08 & 0.84 & 0.96 & 0.86 \\
\hline Slope UB ${ }^{2}$ & 1.75 & 1.02 & 1.19 & 1.09 \\
\hline Intercept & 2.09 & 0.83 & 0.01 & -0.09 \\
\hline Intercept LB & 2.31 & 0.89 & 0.08 & -0.04 \\
\hline Intercept UB & 1.92 & 0.77 & -0.04 & -0.13 \\
\hline $\mathrm{R}$ & 0.17 & 0.54 & 0.71 & 0.79 \\
\hline RMSE (m) & 2.01 & 0.95 & 0.23 & 0.44 \\
\hline Mean Bias (m) & 1.93 & 0.90 & 0.17 & 0.25 \\
\hline
\end{tabular}

\section{Discussion}

For each altimetry cycle of ERS2, ENVISAT, SARAL, and CryoSat-2, the water level of the Arcachon Bay was estimated by computing the median of submerged points, and compared to tide gauge measurements carried out at the same time (in a 5 min interval). Altimetry measurements above emerged points were considered as topography measurements and were compared to the nearest lidar bathymetry points.

Over coastal areas, the altimeter footprint is contaminated by signals from different surface types which reduce the accuracy of the measurements [6]. For water levels estimation, SARAL operating at Ka-band frequency shows significant improvement in the measurement accuracy (vertical resolution) comparing to the ERS-2 and ENVISAT Ku-band altimeters, allowing better observations in coastal areas like lagoons $[38,39]$. This improvement comes from the reduced footprint area $(\sim 6 \mathrm{~km})$ of SARAL which reduces the impact of land on SARAL waveforms. It should be noted that the use of Ka-band is not the only factor that governs the size of the footprint, the larger bandwidth ( $480 \mathrm{MHz})$ used by SARAL has an impact on the footprint size as well. According to [6], SARAL AltiKa's footprint is $\sim 0.8$ times smaller than a Ku-band altimeter for a given bandwidth. CryoSat-2 shows as well major improvements in the accuracy for water levels estimation comparing to ERS-2 and ENVISAT. Operating in the same band $(\mathrm{Ku})$ as the latter missions, the better performance of CryoSat-2 comes from the use of the SAR mode of acquisition. The processing of CryoSat-2 SAR data is based on the delay Doppler technique that reduces the footprint size in the along-track direction which makes CryoSat-2 more suitable for coastal monitoring. The lower consistency with in-situ measurements was obtained using data from LRM missions operating at Ku-band (ERS-2 and ENVISAT) especially at low tides where its spatial resolution could not resolve the complex water-land mixture of the bay. Figure 7 shows that above mean sea level ENVISAT was capable of estimating the water level of the bay with a relatively low bias.

The results also show a great potential for radar altimetry to retrieve the topographic variation of the intertidal zone. SARAL and CryoSat-2 show a large consistency with the lidar measurements. ENVISAT was able to follow the variation of the intertidal zone bathymetry producing a correlation coefficient (R) of 0.57 but with an important bias (due to the large footprint of ENVISAT).

CryoSat-2 was the only mission that flew over the "ile aux oiseaux" sandbank (Figure 1b). Some altimetry measurements made by CryoSat- 2 underestimated the elevation of topography in this area. It is very likely that the cause of the high discrepancy is due to the penetration of the electromagnetic wave in the dry soil (long time after high water). We calculated the maximum penetration depth that corresponds to the electromagnetic wave frequency and the dielectric properties of the sand (Appendix B). The differences obtained between the underestimated measurements made by altimetry and the corresponding lidar measurements are lower than the maximum penetration depth of $1.35 \mathrm{~m}$ which is consistent with our hypothesis. We eliminated the underestimated points 
from CryoSat-2 measurements and we observed an improvement in terms of slope (from 0.96 to 0.98 ), intercept (from -0.09 to -0.08 ), and $R$ (from 0.79 to 0.89 ).

In this study, an automatic classification of cycles was performed to discriminate between submerged and emerged cycles. An automatic process was also envisaged to classify each measurement point, using the backscattering coefficient that tends to increase for land-dominated areas. However, an important limitation was encountered during the automating process. During low tides, some altimetry points above water showed as well high backscattering coefficients, which complicated the separation of emerged and submerged points using the backscattering coefficient parameter. The high values of the backscattering coefficient obtained for water at low tides is most likely due to smoother water surfaces in the channels than in the bay, caused by the reduced wave activity. This reduced roughness increases the specular reflection and thus the power received by the sensor (the backscattering coefficient). An example is shown in Figure 9 (left) for the cycle 20 of SARAL. The backscattering coefficient of water in large channels (zone 5 and zone 3 ) is lower than the backscattering coefficient of water in narrow channels (zone 4 and zone 2) showing values that match land-dominated areas (zone 1).
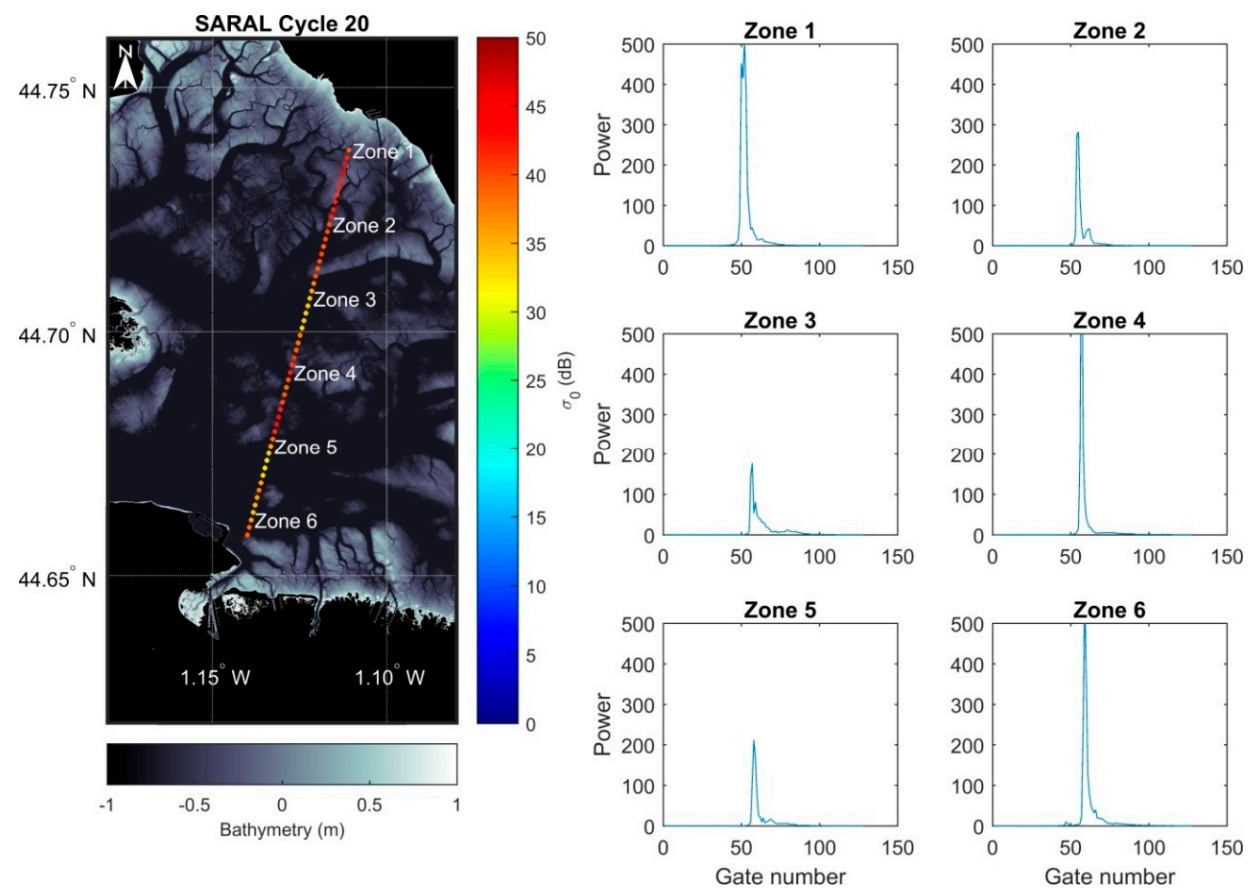

Figure 9. Spatial variation of the backscattering coefficient for SARAL (cycle 20) at low tide along with the corresponding waveforms of the indicated zones.

Figures 9-12 show the spatial variation of the backscattering coefficient for a given cycle and the waveforms corresponding to different points in the bay. Figures 10 and 12 correspond to cycles crossing the bay at high tides for SARAL and CryoSat-2 respectively (same type of figures is available in the supplementary material for ENVISAT (Figures S3 and S4)). For SARAL (Figure 10) and CryoSat-2 (Figure 12), we observe at the middle of the bay (zone 3 and zone 4) that the waveforms look like typical ocean waveforms. However, the waveforms at the edges of the bay (zones 1, 2, 5, and 6 for SARAL and zones 1 and 6 for CryoSat-2) show a sharp rise. It is not the case for ENVISAT at high tides (Figure S3). The waveforms of ENVISAT in the middle of the bay (zone 3 and zone 4) differ from the typical ocean waveforms due to the larger footprint of ENVISAT. It should be noted that the waveforms of CryoSat-2 at high tides maintain typical ocean waveforms closer to the coastline than SARAL due to the SAR mode of CryoSat-2 that increases the resolution in the along-track direction of the satellite. Another consequence of the SAR mode is the highly energetic waveforms. 

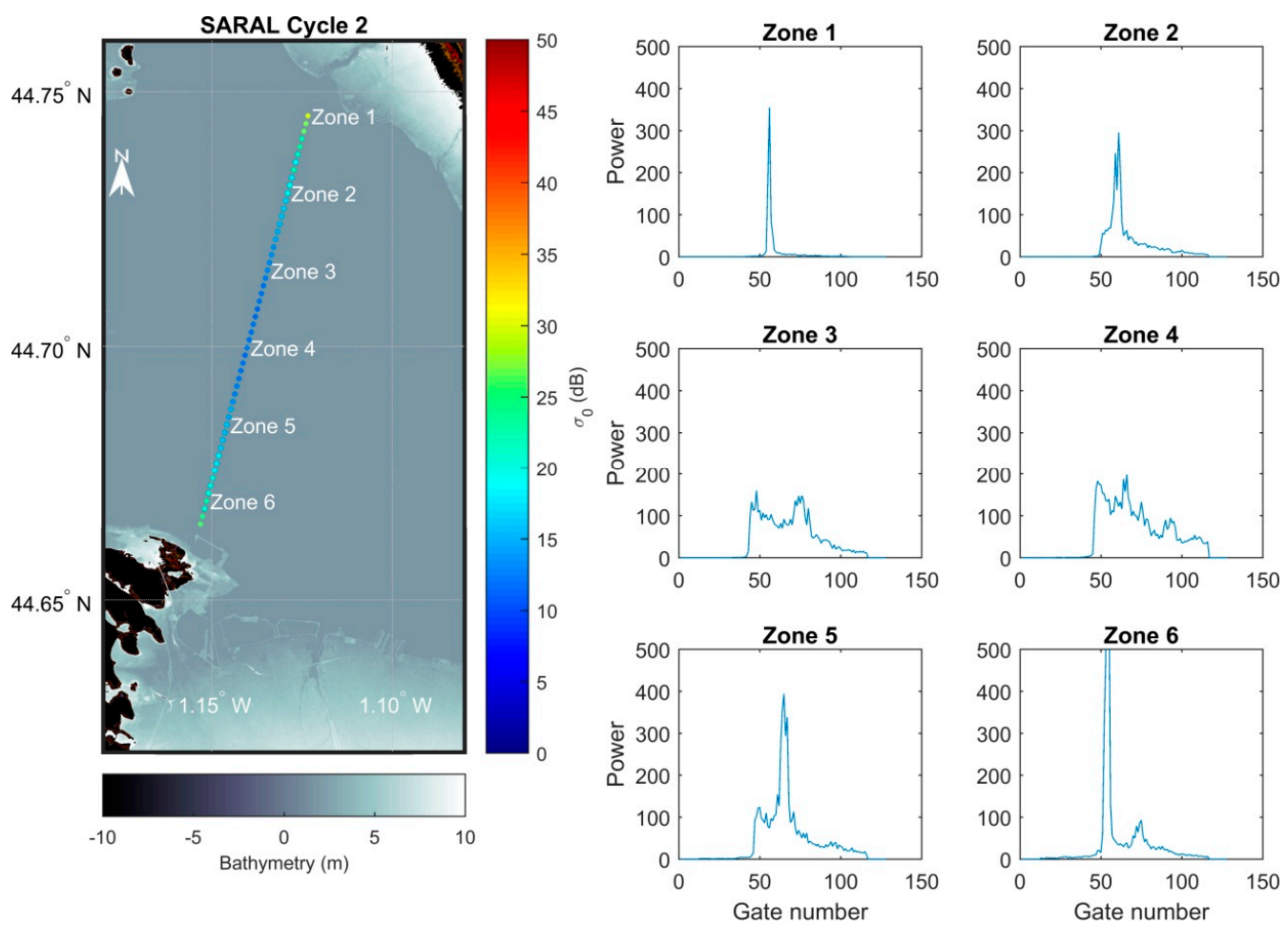

Figure 10. Spatial variation of the backscattering coefficient for SARAL (cycle 2) at high tide along with the corresponding waveforms of the indicated zones.
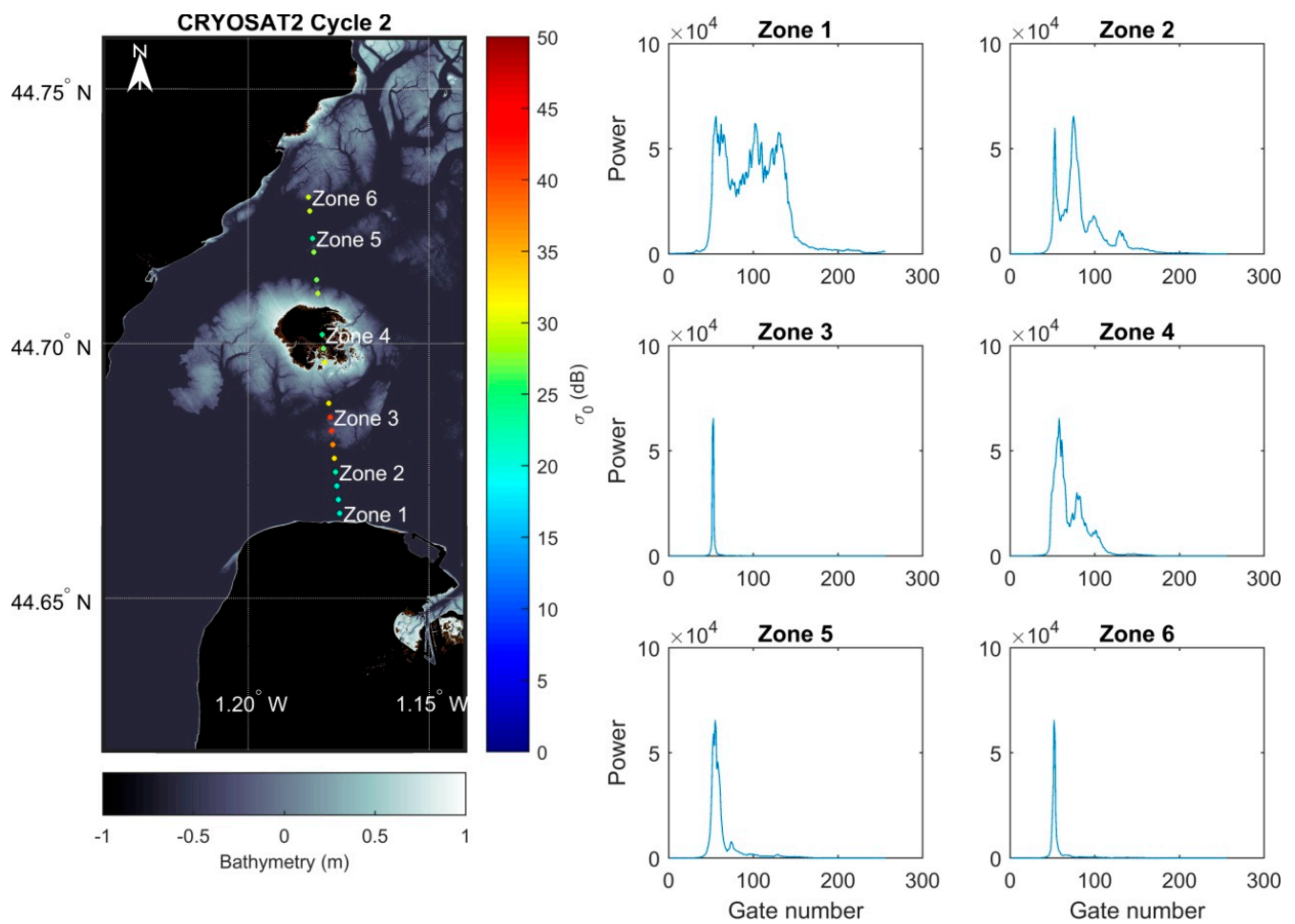

Figure 11. Spatial variation of the backscattering coefficient for CryoSat-2 (cycle 2) at low tide along with the corresponding waveforms of the indicated zones. 

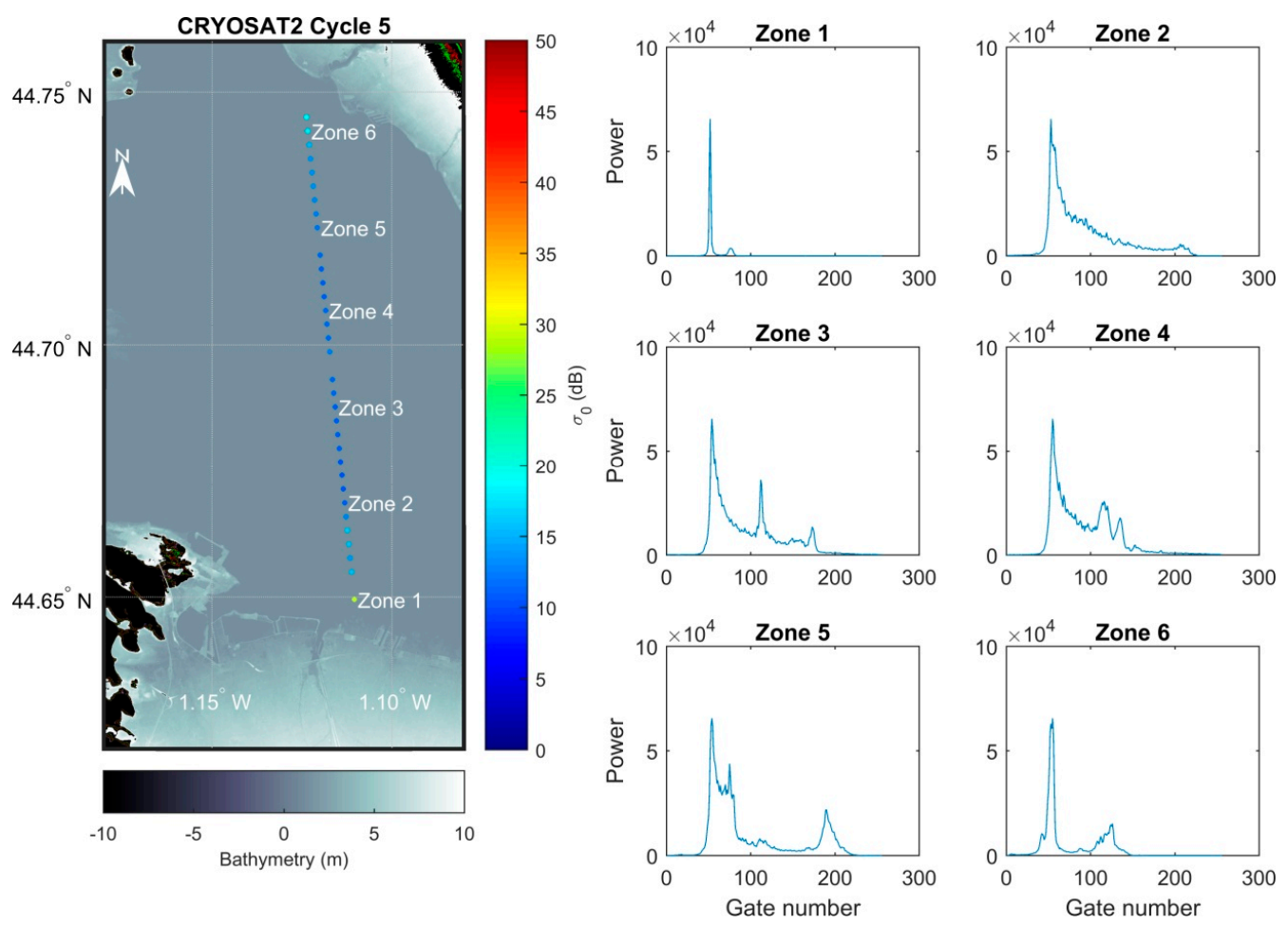

Figure 12. Spatial variation of the backscattering coefficient for CryoSat-2 (cycle 5) at high tide along with the corresponding waveforms of the indicated zones.

Figures 9 and 11 correspond to cycles crossing the bay at low tides for SARAL and CryoSat-2 respectively. At low tides, SARAL (Figure 9) shows peak shaped waveforms (relatively similar to ENVISAT waveforms at low tides (Figure S4)) while CryoSat-2 (Figure 11) shows mixed shaped waveforms. Typical ocean waveforms were not observed for low tides even in areas dominated by water.

The use of satellite radar altimetry to monitor SSH and topography has the potential to be applied in any tidal zone especially in remote areas where no tide gauge record or topography data are available. Radar altimetry parameters ( $\mathrm{SSH}, \sigma_{0}$ and peakiness) can be used to discriminate between high (parameter values almost constant for a given cycle) and low (larger variability) tides. Until now, only large submerged and emerged areas can be discriminated during low tides. Analyses of the radar echoes (waveforms) can provide valuable information to improve the characterization of the nature of the surface (emerged or submerged).

The new-era coastal altimetry satellites contribute to the advancement of coastal ocean observing systems [40]. The launch of the SWOT mission in 2021 will offer new opportunities for monitoring of coastal lagoons topography and changes in time thanks to (i) the acquisitions of elevation along two swaths of $60 \mathrm{~km}$ of width that will provide 2D maps, (ii) its better vertical accuracy, (iii) its shorter repeat period, (iv) the use of the Ka-band that has a smaller penetration depth.

\section{Conclusions}

This study is the first to demonstrate the capabilities of altimetry to retrieve the Sea Surface Height and the topography of the intertidal zone in a coastal lagoon. Data from four altimetry missions were analyzed over Arcachon's Bay coastal lagoon located in the South-East of the Bay of Biscay: (i) ERS-2, (ii) ENVISAT, (iii) SARAL, and (iv) CryoSat-2. The two first missions were operating at Ku-band in low resolution mode whereas SARAL is the first mission to operate in Ka-band in LRM and CryoSat-2 is the first mission to operate at Ku-band in SAR mode. Altimetry measurements were validated using tide gauge and lidar bathymetry datasets. 
Considering data from the classical LRM missions operating at Ku-band (ERS-2 and ENVISAT), SSH and topography retrievals from ERS-2 are inaccurate whereas ENVISAT measurements provide better results for SSH ( $\mathrm{R}>0.82$ and RMSE $<1.04 \mathrm{~m}$ ) than for topography ( $R \sim 0.54$ and RMSE $\sim .95 \mathrm{~m})$. However, SARAL and CryoSat-2 showed very satisfying correspondence with ancillary data with correlation coefficient $(\mathrm{R})$ higher than 0.93 and RMSE lower than $0.42 \mathrm{~m}$ for SSH estimations and R higher than 0.71 for topography with RMSE lower than $0.44 \mathrm{~m}$. It should be noted that the standard deviation of the whole sea level records is $1.05 \mathrm{~m}$.

Furthermore, a successful and simple statistical method (based on a combination of a non-supervised clustering technique and grouping altimetry data into quartiles) was introduced in order to select valid altimetry data. The purpose of this method is to accelerate the processing phase of altimetry data and to optimize the accuracy of Sea Surface Height estimation. This selection method showed very satisfying results with similar accuracy performance as the manual selections made using MAPS software.

The most important limitation lies in the large footprint of altimeters. This coarse resolution prevented us from automatically discriminating land from water using intrinsic altimetry parameters like the backscattering coefficient or waveforms peakiness. However, we were able to discriminate acquisitions made during low tides from the ones made during high tides, because at the scale of the bay good contrast between low and high tides was obtained by the backscattering coefficient and the peakiness.

While altimetry was able to monitor the topography of the bay, caution must be taken when using altimetry data to retrieve topographic variations in similar environments. Dry sandy features are most likely problematic due to the important penetration depth of electromagnetic waves in such mediums. It is recommended to use this approach in areas exposed frequently to water.

Supplementary Materials: The following are available online at www.mdpi.com/2072-4292/10/2/297/s1, Figure S1: $(a, b)$ Examples of ERS-2 along-track profiles of altimetry height over water (purple crosses) and land (green crosses) at high (a) and low (b) tides, the topography under the altimeter ground track is represented in brown and it is filled with water (in blue) using leveled tide-gauge records; (c,d) Variation of Ice-1 backscattering coefficients of Ku-band (black dots) at high (c) and low (d) tides., Figure S2: (a,b) Examples of ENVISAT along-track profiles of altimetry height over water (purple crosses) and land (green crosses) at high (a) and low (b) tides, the topography under the altimeter ground track is represented in brown and it is filled with water (in blue) using leveled tide-gauge records; (c,d) Variation of Ice-1 backscattering coefficients of Ku-band (black dots) at high $(\mathrm{c})$ and low $(\mathrm{d})$ tides. Figure S3: Spatial variation of the backscattering coefficient for ENVISAT (cycle 21) at high tide along with the corresponding waveforms of the indicated zones. Figure S4: Spatial variation of the backscattering coefficient for ENVISAT (cycle 9) at low tide along with the corresponding waveforms of the indicated zones.

Acknowledgments: This work was supported by the CNES. It is based on SWOT space mission and the SWOT COTEST project and was also supported by the Normandy Region.

Author Contributions: Edward Salameh and Frédéric Frappart conceived and designed the experiments; Edward Salameh, Frédéric Frappart, Alexandra Spodar, Vincent Marieu, and Jean-Paul Parisot performed the experiments and analyzed the data; Edward Salameh and Frédéric Frappart wrote the paper. All authors were involved in the analysis of the results and contributed to the discussion of results and the preparation of the manuscript.

Conflicts of Interest: The authors declare no conflict of interest.

\section{Appendix A.}

The Ice-1 (OCOG-Offset Centre of Gravity) retracking algorithm approach consists of replacing the waveform with a box that has the same center of gravity as the waveform. The box is defined using three measurements:

$$
\begin{gathered}
\text { centre of gravity }=\frac{\sum_{\mathrm{n}=1+\operatorname{aln}}^{\mathrm{n}=\mathrm{N}-\mathrm{aln}} \mathrm{ny}^{2}(\mathrm{n})}{\sum_{\mathrm{n}=1+\mathrm{aln}}^{\mathrm{n}=\mathrm{N}-\mathrm{aln}} \mathrm{y}^{2}(\mathrm{n})} \\
\text { amplitude }=\sqrt{\frac{\sum_{\mathrm{n}=1+\mathrm{aln}}^{\mathrm{n}=\mathrm{N}-\mathrm{aln}} \mathrm{y}^{4}(\mathrm{n})}{\sum_{\mathrm{n}=1+\operatorname{aln}}^{\mathrm{n}=\mathrm{N}-\mathrm{aln}} \mathrm{y}^{2}(\mathrm{n})}}
\end{gathered}
$$




$$
\text { width }=\frac{\left(\sum_{\mathrm{n}=1+\mathrm{aln}}^{\mathrm{n}=\mathrm{N}-\mathrm{aln}} \mathrm{y}^{2}(\mathrm{n})\right)^{2}}{\sum_{\mathrm{n}=1+\mathrm{aln}}^{\mathrm{n}=\mathrm{N}-\mathrm{aln}} \mathrm{y}^{4}(\mathrm{n})}
$$

where $\mathrm{N}$ is the total gate number, aln is the number of eliminated gate in the starting and ending of waveform and $y(n)$ is the power of the nth gate. The middle of the leading edge point (LEP) is given by:

$$
\mathrm{LEP}=\text { centre of gravity }-0.5 \times \text { width }
$$

Peakiness is a measure of how sharply peaked an echo is. It is the ratio of the maximum power (highest bin value) to the accumulated echo power above the retracking point. The peakiness in AltiKa GDR is given by:

$$
\text { Peakiness }_{\text {AltiKa }}=\frac{\mathrm{P}_{\max } \times \mathrm{N}_{\text {right }}}{\sum_{\mathrm{i}=1}^{\mathrm{N}_{W F}} \mathrm{P}_{\mathrm{i}}}
$$

where $\mathrm{N}_{\mathrm{WF}}$ is the total number of the registering gates, and $\mathrm{N}_{\text {right }}$ is a number of points to the right from the tracking point (i.e., above the retracking point). For SIRAL:

$$
\text { Peakiness SIRAL }=\frac{P_{\max } \times 30}{\sum_{i=1}^{N_{W F}} P_{i}}
$$

\section{Appendix B.}

The penetration depth $(\delta \mathrm{p})$ of an electromagnetic wave in an homogeneous medium can be expressed as a function of its dielectric permittivity. According to [41], it can be written as follows:

$$
\delta_{\mathrm{p}}=\frac{\lambda \sqrt{\varepsilon \prime}}{2 \pi \varepsilon^{\prime \prime}}
$$

where $\lambda$ is the wavelength of the electromagnetic wave, $\varepsilon$ and $\varepsilon^{\prime \prime}$ are the real and complex parts of the dielectric permittivity respectively. Empirical relationships between dielectric permittivity $(\varepsilon)$ and soil nature and its water content were established. In this study, we used the empirical relationships from [42] that have the following form:

$$
\varepsilon=a_{0}+a_{1} S+a_{2} C+\left(b_{0}+b_{1} S+b_{2} C\right) m_{v}+\left(c_{0}+c_{1} S+c_{2} C\right) m_{v}
$$

where $S$ and $C$ are the sand and clay fraction of soil given in percent, $m_{v}$ is the volumetric water content given in percent, $a_{0}, a_{1}, a_{2}, b_{0}, b_{1}, b_{2}, c_{0}, c_{1}, c_{2}$ are the constants of the empirical relationship given in Table 2 of (Hallikainen et al., 1985).

Maximum penetration depth are obtained for dry soils (i.e., $m_{v}=0$ ). (A1) becomes:

$$
\max \left(\delta_{\mathrm{p}}\right)=\frac{\lambda \sqrt{a_{0} \prime+a_{1} \prime S+a_{2} / C}}{2 \pi\left(a_{0}^{\prime \prime}+a_{1}^{\prime \prime} S+a_{2}^{\prime \prime} C\right)}
$$

Over the sandbank known as "île aux oiseaux", we consider $S=100$ and $C=0$. This latter equation becomes:

$$
\max \left(\delta_{\mathrm{p}}\right)=\frac{\lambda \sqrt{a_{0} \prime+100 a_{1}^{\prime}}}{2 \pi\left(a_{0}^{\prime \prime}+100 a_{1}^{\prime \prime}\right)}
$$

\section{References}

1. Agardy, T.; Alder, J. Coastal Systems. In Ecosystems and Human Well-Being: Current State and Trends; Hassan, R., Scholes, R., Ash, N., Eds.; Island Press: Washington, DC, USA, 2005; pp. 513-550.

2. CIESIN-Center for International Earth Science Information Network. Gridded Population of the World (GPW) Version 3 Beta. Available online: http:/ / sedac.ciesin.columbia.edu (accessed on 20 September 2017). 
3. Barnes, R.S.K. Coastal Lagoons (Cambridge Studies in Modern Biology 1); Cambridge University Press: Cambridge, UK, 1980.

4. Kjerfve, B.; Magill, K.E.; Baruch, B.W. Geographic and hydrodynamic characteristics of shallow coastal lagoons. Mar. Geol. 1989, 88, 187-199. [CrossRef]

5. Chapman, P.M. Management of coastal lagoons under climate change. Estuar. Coast. Shelf Sci. 2012, 110, 32-35. [CrossRef]

6. Vignudelli, S.; Kostianoy, A.G.; Cipollini, P.; Benveniste, J. (Eds.) Coastal Altimetry; Springer: Berlin/Heidelberg, Germany, 2011.

7. Cipollini, P.; Calafat, F.M.; Jevrejeva, S.; Melet, A.; Prandi, P. Monitoring Sea Level in the Coastal Zone with Satellite Altimetry and Tide Gauges. Surv. Geophys. 2017, 38, 33-57. [CrossRef]

8. Deborde, J.; Anschutz, P.; Auby, I.; Glé, C.; Commarieu, M.-V.; Maurer, D.; Lecroart, P.; Abril, G. Role of tidal pumping on nutrient cycling in a temperate lagoon (Arcachon Bay, France). Mar. Chem. 2008, 109, 98-114. [CrossRef]

9. Plus, M.; Dumas, F.; Stanisiè Re, J.-Y.; Maurer, D. Hydrodynamic characterization of the Arcachon Bay, using model-derived descriptors. Cont. Shelf Res. 2009, 29, 1008-1013. [CrossRef]

10. Rimmelin, P.; Dumon, J.-C.; Maneux, E.; Gonçalves, A. Study of Annual and Seasonal Dissolved Inorganic Nitrogen Inputs into the Arcachon Lagoon, Atlantic Coast (France). Estuar. Coast. Shelf Sci. 1998, 47, 649-659. [CrossRef]

11. Blanchet, H.; De Montaudouin, X.; Chardy, P.; Bachelet, G. Structuring factors and recent changes in subtidal macrozoobenthic communities of a coastal lagoon, Arcachon Bay (France). Estuar. Coast. Shelf Sci. 2005, 64, 561-576. [CrossRef]

12. Envisat, C.Z. RA-2 Advanced Radar Altimeter: Instrument Design and Pre-Launch Performance Assessment Review. Acta Astronaut. 1999, 44, 323-333.

13. Verron, J.; Sengenes, P.; Lambin, J.; Noubel, J.; Steunou, N.; Guillot, A.; Picot, N.; Coutin-Faye, S.; Sharma, R.; Gairola, R.M.; et al. The SARAL/AltiKa Altimetry Satellite Mission. Mar. Geodesy 2015, 38, 2-21. [CrossRef]

14. Nielsen, K.; Stenseng, L.; Andersen, O.; Knudsen, P. The Performance and Potentials of the CryoSat-2 SAR and SARIn Modes for Lake Level Estimation. Water 2017, 9, 374. [CrossRef]

15. Wingham, D.J.; Francis, C.R.; Baker, S.; Bouzinac, C.; Brockley, D.; Cullen, R.; de Chateau-Thierry, P.; Laxon, S.W.; Mallow, U.; Mavrocordatos, C.; et al. CryoSat: A mission to determine the fluctuations in Earth's land and marine ice fields. Adv. Space Res. 2006, 37, 841-871. [CrossRef]

16. Frappart, F.; Blumstein, D.; Cazenave, A.; Ramillien, G.; Birol, F.; Morrow, R.; Rémy, F. Satellite Altimetry: Principles and Applications in Earth Sciences. In Wiley Encyclopedia of Electrical and Electronics Engineering; John Wiley \& Sons, Inc.: Hoboken, NJ, USA, 2017; pp. 1-25.

17. Chelton, D.B.; Ries, J.C.; Haines, B.J.; Fu, L.L.; Callahan, P.S. Satellite Altimetry. In Satellite Altimetry and the Earth Sciences: A Handbook of Techniques and Applications; Fu, L.L., Cazenave, A., Eds.; Academic Press: San Diego, CA, USA, 2001; pp. 1-131.

18. Frappart, F.; Fatras, C.; Mougin, E.; Marieu, V.; Diepkilé, A.T.; Blarel, F.; Borderies, P. Radar altimetry backscattering signatures at Ka, Ku, C, and S bands over West Africa. Phys. Chem. Earth 2015, 83-84, 96-110. [CrossRef]

19. Frappart, F.; Roussel, N.; Biancale, R.; Martinez Benjamin, J.J.; Mercier, F.; Perosanz, F.; Garate Pasquin, J.; Martin Davila, J.; Perez Gomez, B.; Gracia Gomez, C.; et al. The 2013 Ibiza Calibration Campaign of Jason-2 and SARAL Altimeters. Mar. Geodesy 2015, 38, 219-232. [CrossRef]

20. Biancamaria, S.; Frappart, F.; Leleu, A.-S.; Marieu, V.; Blumstein, D.; Desjonquères, J.-D.; Boy, F.; Sottolichio, A.; Valle-Levinson, A. Satellite radar altimetry water elevations performance over a $200 \mathrm{~m}$ wide river: Evaluation over the Garonne River. Adv. Space Res. 2017, 59, 128-146. [CrossRef]

21. Frappart, F.; Papa, F.; Marieu, V.; Malbeteau, Y.; Jordy, F.; Calmant, S.; Durand, F.; Bala, S. Preliminary Assessment of SARAL/AltiKa Observations over the Ganges-Brahmaputra and Irrawaddy Rivers. Mar. Geodesy 2015, 38, 568-580. [CrossRef]

22. Gaspar, P.; Ogor, F.; Le Traon, P.-Y.; Zanife, O.-Z. Estimating the sea state bias of the TOPEX and POSEIDON altimeters from crossover differences. J. Geophys. Res. 1994, 99, 24981-24994. [CrossRef]

23. Parisot, J.-P.; Diet-Davancens, J.; Sottolichio, A.; Crosland, E.; Drillon, C.; Verney, R. Modélisation des agitations dans le bassin d'Arcachon. Xèmes Journées Sophia Antip. 2008, 435-444. [CrossRef] 
24. Cartwright, D.E.; Edden, A.C. Corrected Tables of Tidal Harmonics. Geophys. J. R. Astron. Soc. 1973, 33, 253-264. [CrossRef]

25. Wahr, J.M. Deformation induced by polar motion. J. Geophys. Res. Solid Earth 1985, 90, 9363-9368. [CrossRef]

26. Wingham, D.J.; Rapley, C.G.; Griffiths, H. New Techniques in Satellite Altimeter Tracking Systems. In Proceedings of the IGARSS 86 Symposium, Zurich, Switzerland, 8-11 September 1986; pp. 1339-1344.

27. Bamber, J.L. Ice sheet altimeter processing sheme. Int. J. Remote Sens. 1994, 15, 925-938. [CrossRef]

28. Frappart, F.; Minh, K.D.; L’hermitte, J.; Cazenave, A.; Ramillien, G.; Le Toan, T.; Mognard-Campbell, N. Water volume change in the lower Mekong from satellite altimetry and imagery data. Geophys. J. Int. 2006, 167, 570-584. [CrossRef]

29. Frappart, F.; Calmant, S.; Cauhopé, M.; Seyler, F.; Cazenave, A. Preliminary results of ENVISAT RA-2-derived water levels validation over the Amazon basin. Remote Sens. Environ. 2006, 100, 252-264. [CrossRef]

30. Laxon, S. Sea ice altimeter processing scheme at the EODC. Int. J. Remote Sens. 1994, 15, 915-924. [CrossRef]

31. Jekeli, C. Geometric Reference System in Geodesy; Division of Geodesy and Geospatial Science School of Earth Sciences, Ohio State University: Columbus, OH, USA, 2006.

32. SHOM. Références Altimétriques Maritimes (RAM). Available online: http://diffusion.shom.fr/ (accessed on 10 February 2018).

33. Hartigan, J.A.; Wong, M.A. A K-Means Clustering Algorithm. J. R. Stat. Soc. 1979, 28, 100-108.

34. Craw, S. Manhattan Distance. In Encyclopedia of Machine Learning; Sammut, C., Webb, G.I., Eds.; Springer Science \& Business Media: Boston, MA, USA, 2011.

35. Passing, H.; Bablok, W. A new biometrical procedure for testing the equality of measurements from two different analytical methods. J. Clin. Chem. Clin. Biochem. 1983, 21, 709-720. [PubMed]

36. Cancet, M.; Bijac, S.; Chimot, J.; Bonnefond, P.; Jeansou, E.; Laurain, O.; Lyard, F.; Bronner, E.; Féménias, P. Regional in situ validation of satellite altimeters: Calibration and cross-calibration results at the Corsican sites. Adv. Space Res. 2013, 51, 1400-1417. [CrossRef]

37. Ménard, Y.; Jeansou, E.; Vincent, P. Calibration of the TOPEX/POSEIDON altimeters at Lampedusa: Additional results at Harvest. J. Geophys. Res. 1994, 99, 24487. [CrossRef]

38. Vu, P.; Frappart, F.; Darrozes, J.; Marieu, V.; Blarel, F.; Ramillien, G.; Bonnefond, P.; Birol, F.; Blarel, F. Multi-Satellite Altimeter Validation along the French Atlantic Coast in the Southern Bay of Biscay from ERS-2 to SARAL. Remote Sens. 2018, 10, 93. [CrossRef]

39. Bonnefond, P.; Verron, J.; Aublanc, J.; Babu, K.; Bergé-Nguyen, M.; Cancet, M.; Chaudhary, A.; Crétaux, J.-F.; Frappart, F.; Haines, B.; et al. The Benefits of the Ka-Band as Evidenced from the SARAL/AltiKa Altimetric Mission: Quality Assessment and Unique Characteristics of AltiKa Data. Remote Sens. 2018, 10, 83. [CrossRef]

40. Liu, Y.; Kerkering, H.; Weisberg, R.H. Coastal Ocean Observing Systems; Elsevier (Academic Press): London, UK, 2015.

41. Ulaby, F.; Moore, R.; Fung, A. Microwave Remote Sensing: Active and Passive. Volume 2, Radar Remote Sensing and Surface Scattering and Emission Theory; Addison-Wesley: Boston, MA, USA, 1982.

42. Hallikainen, M.; Ulaby, F.; Dobson, M.; El-rayes, M.; Wu, L. Microwave Dielectric Behavior of Wet Soil-Part 1: Empirical Models and Experimental Observations. IEEE Trans. Geosci. Remote Sens. 1985, GE-23, 25-34. [CrossRef]

(C) 2018 by the authors. Licensee MDPI, Basel, Switzerland. This article is an open access article distributed under the terms and conditions of the Creative Commons Attribution (CC BY) license (http://creativecommons.org/licenses/by/4.0/). 